\title{
əImprovements in Supercooled Liquid Water Simulations of Low-Level Mixed-Phase Clouds over the Southern Ocean Using a Single-Column Model
}

\author{
TATSUYA SEIKI \\ Japan Agency for Marine-Earth Science and Technology, Yokohama, Japan \\ WoOsub RoH \\ Atmosphere and Ocean Research Institute, The University of Tokyo, Tokyo, Japan
}

(Manuscript received 30 September 2019, in final form 12 August 2020)

\begin{abstract}
A high-resolution global atmospheric model, the nonhydrostatic icosahedral atmospheric model (NICAM), exhibited underestimation biases in low-level mixed-phase clouds in the midlatitudes and polar regions. The ice-cloud microphysics used in a single-moment bulk cloud microphysics scheme (NSW6) was evaluated and improved using a singlecolumn model by reference to a double-moment bulk cloud microphysics scheme (NDW6). Budget analysis indicated that excessive action of the Bergeron-Findeisen and riming processes crucially reduced supercooled liquid water. In addition, the rapid production of rain directly reduced cloud water and indirectly reduced cloud water through the production of snow and graupel by riming. These biases in growth rates were found to originate from the number concentration diagnosis used in NSW6. The diagnosis based on the midlatitude cloud systems assumption was completely different from the one for lowlevel mixed-phase clouds. To alleviate underestimation biases, rain production, heterogeneous ice nucleation, vapor deposition by snow and graupel, and riming processes were revised. The sequential revisions of cloud microphysics alleviated the underestimation biases step by step without parameter tuning. The lifetime of cloud layers simulated by NSW6 was reasonably prolonged.
\end{abstract}

KEYWORDS: Southern Ocean; Cloud microphysics; Cloud water/phase; Climate models; Model evaluation/performance; Single column models

\section{Introduction}

Low-level clouds are broadly distributed over the midlatitudes and polar regions. In particular, low-level clouds over the polar regions consist of mixed-phase cloud layers above the freezing level at subzero temperatures, and hence, their microphysical properties and maintenance mechanisms are unique compared with ones in different regions (Morrison et al. 2012). In addition, the low-level clouds have strong shortwave reflectance in the summer hemisphere and longwave absorption throughout the year (Curry et al. 1996). Such strong cloud radiative forcing itself induces various climate feedbacks (Curry et al. 1996) and the north-south interhemispheric contrast in cloud radiative forcing can induce additional climate feedbacks through general circulation (e.g., Kang et al. 2009). Low-level mixed-phase clouds have concerned climate researchers widely, especially after the First International Satellite Cloud Climatology Project (ISCCP) Regional Experiment (FIRE)-Arctic Cloud Experiment (ACE) (Curry et al. 2000) and the Surface Heat Budget of the Arctic Ocean (SHEBA) program (Uttal et al. 2002), and issues related to the low-level mixed-phase clouds in climate have been organized in following observation campaigns [e.g., the Mixed-Phase Arctic Cloud Experiment (M-PACE)

¿ Denotes content that is immediately available upon publication as open access.

Corresponding author: Tatsuya Seiki, tseiki@jamstec.go.jp summarized by Verlinde et al. (2007)]. Nevertheless, the fifth phase of the Coupled Model Intercomparison Project (CMIP5) general circulation models (GCMs) commonly showed significant biases in shortwave cloud radiative forcing (SWCRF) over the Southern Ocean (Bodas-Salcedo et al. 2012; Williams et al. 2013). Bodas-Salcedo confirmed that the SWCRF bias mainly originated from underestimation of supercooled liquid water in low-level mixed-phase clouds. Large intermodal spread in supercooled liquid water over the mid- to highlatitude regions results in large uncertainties in cloud feedbacks (e.g., McCoy et al. 2015).

The SWCRF bias mainly originates from poor representation of cloud microphysics for low-level mixed-phase clouds although the bias partially originates from underestimation of sea ice over the Southern Ocean through ocean general circulation (Tatebe et al. 2018). For example, Field et al. (2014) used a numerical weather prediction model (the Unified Model) with a $1.5-\mathrm{km}$ horizontal resolution and a singlemoment bulk cloud microphysics scheme and showed that turbulent processes and ice-cloud microphysics have a significant impact on the reproducibility of arctic low-level mixed-phase clouds. Their simulations partially improved after modifying the atmospheric processes but the bias still remained. Furtado and Field (2017) further revised ice cloud microphysics (vapor deposition and riming) in the Unified Model and finally improved the bias. Morrison and Pinto (2005) effectively simulated the Arctic low-level mixed-phase clouds by using a newly developed double-moment bulk cloud microphysics scheme with detailed ice nucleation 
(a) NSW6 (JJA, 2004)

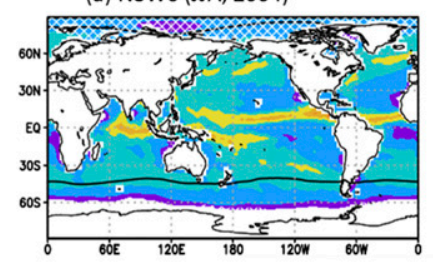

(b) NDW6 (JJA, 2004)

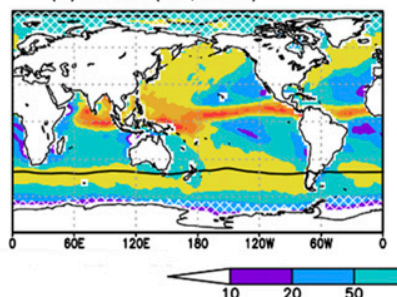

(c) Obs. MAC-LWP (JJA, 1988-2016)

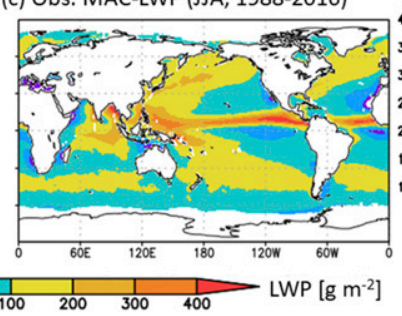

(d) Zonal Mean

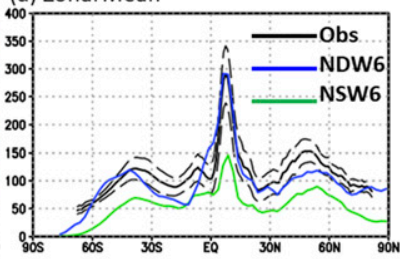

FIG. 1. Global distribution of liquid water paths $\left(\mathrm{g} \mathrm{m}^{-2}\right)$ for July-August from the (a) NICAM simulation with NSW6, (b) NICAM simulation with NDW6, and (c) satellite product of MAC-LWP (Elsaesser et al. 2017). (d) Zonal mean values of total liquid water path $\left(\mathrm{g} \mathrm{m}^{-2}\right)$ (solid lines) and the error range of the observation (dashed lines). Monthly mean total liquid water path (cloud water path + rainwater path) data were used for the comparison. Polar regions covered by sea ice are shown by white hatching, and 273-K isotherms at $850 \mathrm{hPa}$ are shown by black solid lines in (a) and (b). Here, MAC-LWP were retrieved by mainly combining multiple microwave radiometers on satellites, and thus LWP over sea ice were not analyzed in the algorithm. The zonal mean values of the model results are calculated only over the ocean.

processes despite the use of a numerical weather prediction model [the Fifth-generation Pennsylvania State UniversityNCAR Mesoscale Model (MM5)] with a 20-km horizontal resolution. Recently, GCM simulations confirmed that an increase in supercooled liquid water in subgrid cloud schemes drastically improved the bias in SWCRF over the Southern Ocean (Forbes and Ahlgrimm 2014; Kay et al. 2016; Kawai et al. 2019).

It is necessary to establish how to detect modeling problems and improve ice cloud microphysics for high-resolution GCMs because their computational cost is too expensive to perform evaluation experiments comprehensively. The ongoing CMIP6 is organizing an intercomparison of high-resolution GCMs, named HighResMIP (Haarsma et al. 2016; Roberts et al. 2018). The GCM community expects cloud processes to be improved by increasing model resolutions up to $25 \mathrm{~km}$, which is comparable to the one used in Morrison and Pinto (2005). However, most GCMs in the HighResMIP still use conventional cloud microphysics with subgrid cumulus parameterizations as used for coarse climate simulations so far. For such high-resolution GCMs, cloud microphysics is to be explicitly calculated as is done in numerical weather forecasting models. One of the participating models in the HighResMIP, the nonhydrostatic icosahedral atmospheric model (NICAM) (Tomita and Satoh 2004; Satoh et al. 2008, 2014) provides several options for cloud microphysics schemes without subgrid cumulus parameterizations [see the summary article by Satoh et al. (2018)] and its cloud-related processes were revised compared to various satellite observations and in situ observations (Iga et al. 2007; Kodama et al. 2012; Roh and Satoh 2014; Roh et al. 2017; Seiki et al. 2014, 2015b). Nevertheless, the SWCRF bias was also found in NICAM global simulations (Kodama et al. 2015; Hashino et al. 2016). This study deals with the bias found in NICAM similarly to the study of Furtado and Field (2017) with the Unified Model.

Low-level mixed-phase clouds simulated by NICAM were analyzed in depth by Roh et al. (2020) using the CloudAerosol Lidar and Infrared Pathfinder Satellite Observations (CALIPSO) satellite product and a satellite signal simulator. The vertical profile of low-level mixed-phase clouds is characterized by strong/weak lidar backscatter and a small/large depolarization ratio at the cloud top/bottom (e.g., Shupe 2011; Morrison et al. 2012). This structure means that liquid water concentrates near the cloud top in supercooled conditions and light ice precipitation occurs below the liquid cloud layer. Interestingly, the NICAM simulation with a doublemoment bulk cloud microphysics scheme with six water categories (hereinafter NDW6; Seiki and Nakajima 2014; Seiki et al. 2014, 2015b) effectively captured long-lived low-level mixed phase clouds over the Southern Ocean whereas the NICAM simulation with a single-moment bulk cloud microphysics scheme with six water categories (hereinafter NSW6; Tomita 2008; Kodama et al. 2012; Roh and Satoh 2014; Roh et al. 2017) underestimated supercooled liquid water and represented small amounts of low-level ice clouds. Roh et al. (2020) suggested that the underestimation of supercooled liquid water in the NICAM simulation with NSW6 was related to small ice effective radii and large ice water content. However, ice-cloud microphysical mechanisms that induced the bias were not fully understood only from their satellite analyses. Therefore, this study aims at a systematic understanding of which cloud microphysics processes contribute to the underestimation of the low-level mixed-phase clouds and to clarify how single-moment bulk cloud microphysics schemes can be improved.

Here, we confirm that NDW6 effectively simulates liquid clouds in terms of climatology, whereas Roh et al. (2020) evaluated the scheme within only seven days. We used the 3-month simulation data from Seiki et al. (2015a) and the observation data from the multisensor advanced climatology of liquid water path (MAC-LWP) product (Elsaesser et al. 2017). Uncertainties in the retrieval method for the observational data are summarized in O'Dell et al. (2008). Note that the difference in the LWP distribution between the global simulation with an old version of NSW6 (Kodama et al. 2012) and the one with the latest version of NSW6 (Roh et al. 2017) is small (not shown). Figure 1 shows the comparison of the seasonal mean values of the LWP from NSW6, NDW6, and satellite observations. We can clearly see that the global simulation with NSW6 generally underestimates LWP. In contrast, the global simulation with NDW6 shows good agreement with observations. In particular, LWP south of $45^{\circ} \mathrm{S}$ (cf. $273-\mathrm{K}$ 
isotherms in Fig. 1), which is assumed to be in a supercooled condition, is quantitatively reproduced. Thus, the systematic bias in cloud processes is similar between the short-term and climate simulations as also suggested by past studies (Phillips et al. 2007, hereinafter P07; Martin et al. 2010; Williams et al. 2013; Seiki et al. 2015a).

The bias in the NSW6 simulation mainly originated from fast cloud microphysics processes without dynamical feedbacks. Figure 2 shows the time series of zonal mean values of LWP at $60^{\circ} \mathrm{S}$ from the global simulations using NSW6 and NDW6 (Seiki et al. 2015a). In the initial conditions, specific humidity was provided from the reanalysis dataset but the hydrometeors mixing ratios were not provided. The turbulence processes produce boundary layer clouds within a few hours and then LWP gradually develops by the end of the first day. The departure of LWP between the two microphysical schemes is found even within the first few time steps. Therefore, it is expected that intensive comparison of individual cloud microphysics processes between NSW6 and NDW6 reveals the origin of the bias.

It serves broader modeling community to show how to improve single-cloud microphysics schemes although doublemoment bulk cloud microphysics schemes are generally superior to single-moment bulk cloud microphysics schemes (e.g., Wacker and Seifert 2001; Milbrandt and Yau 2005; Igel et al. 2015; Seiki et al. 2015a). Single-moment bulk cloud microphysics schemes have been widely used for cloudresolving simulations because of their simple formulation and cheaper computational cost (e.g., the computational cost of global simulations with NDW6 is approximately twice as large as the cost with NSW6). Recently, high-resolution GCMs with kilometer-scale horizontal resolutions has been developed (Satoh et al. 2019). In the intercomparison project of the high-resolution GCMs (Stevens et al. 2019), most participants do not employ double-moment bulk cloud microphysics schemes so far. Hence, insights drawn from this study should be shared among, for example, such a highresolution GCM community.

In this study, first, the error sources for LWP underestimation from the NSW6 simulation were detected by comparing these results to the results from the NDW6 simulation. A single-column model with a typical environmental condition of low-level mixed-phase clouds over the Southern Ocean was used for the comparison. Utility of single-column models to capture low-level mixed-phase clouds was found in Klein et al. (2009). We demonstrate how to improve the biases through sensitivity experiments, step by step. In section 2 , the singlecolumn model and its settings are described. In section 3, budget analysis and a series of sensitivity experiments are shown. In section 4, representativeness of the single-column model and a fundamental issue in single-moment bulk cloud microphysics schemes are discussed. A brief summary is given in section 5 .

\section{Single-column model}

\section{a. Numerical setting}

The single-column model is designed to selectively exclude physical processes and external forcing. In this study,

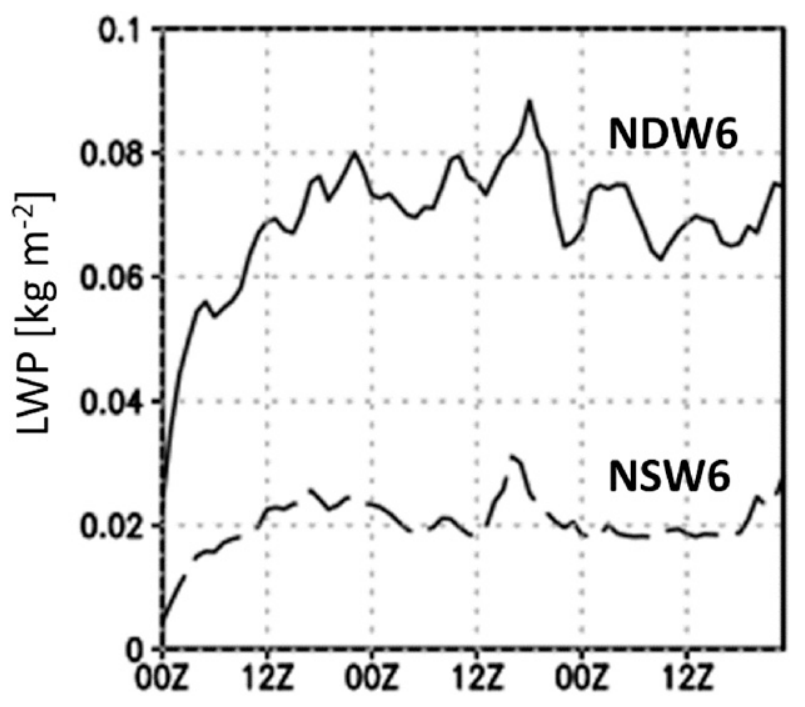

FIG. 2. Time series of the zonal mean value of the LWP $\left(\mathrm{g} \mathrm{m}^{-2}\right)$ from the global simulation with NDW6 and the global simulation with NSW6 at $60^{\circ} \mathrm{S}$.

only cloud microphysics and gravitational sedimentation is calculated in an atmospheric column. This model is so simple that a number of sensitivity experiments are tested at low computational cost. Calculation modules for the physical processes were imported from the general circulation model, NICAM. Since physical processes in most GCMs are designed as vertically one-dimensional structures, our methodology is easily applicable to other GCMs. The cloud microphysics schemes are briefly described in the following subsection.

Initial conditions are given from the aforementioned global simulation with NDW6. Figure 3 shows a sample synoptic image of LWP and anomalies in sea level pressures from the zonal mean daily values. In extratropical cyclone systems, lowlevel clouds are often observed behind the cold front since the cloud top is capped by the synoptic-scale subsidence in such the cold air region. Large LWP values are found in the west to north part of extratropical cyclones in the Southern Hemisphere, as is known (e.g., Bodas-Salcedo et al. 2012; Williams et al. 2013). For reference, vertical profiles of typical mixed-phase low-level clouds are shown in Fig. 4. We chose the atmosphere at $105^{\circ} \mathrm{E}$ and $50^{\circ}-60^{\circ} \mathrm{S}$, where atmospheric temperatures and cloud water profiles show characteristics of low-level mixed-phase clouds: cloud tops are capped at the atmospheric boundary layer, the cloud layer has a thickness of several hundred meters, an inversion layer exists near the cloud top, and the cloud water is in a supercooled condition. Focusing on the cloud structure, the mixing ratios of cloud water linearly increase as altitude increases. This is known to be a typical structure of cloud water that develops mainly by condensational growth in the ascending air parcel. Rain droplets do not develop and ice particles are occasionally produced in the low-level clouds represented in the global simulation with NDW6. 


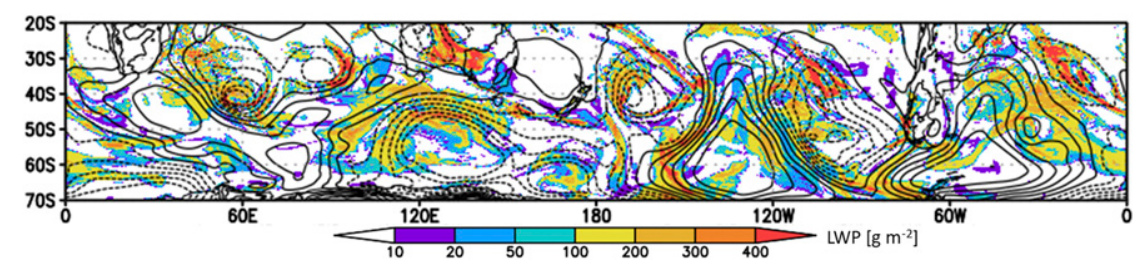

FIG. 3. Horizontal distributions of LWP $\left(\mathrm{g} \mathrm{m}^{-2}\right)$ from the global simulation with NDW6 at 0600 UTC 1 Jun 2004. Black solid or dashed lines indicate the positive or negative anomalies, respectively, in the sea level pressure $(\mathrm{hPa})$, with a 4-hPa interval. The anomaly is defined by taking the difference between instantaneous values and the zonal mean daily values at each latitude.

We simplified the profiles of the atmospheric temperature $T_{a}$ and mixing ratio of cloud water $q_{c}$ to be proportional to altitude and then prepared the initial and environmental conditions for the single-column model (see black solid line in Fig. 4). The initial mixing ratio of cloud water $q_{c}$ at a given altitude $z_{k}$ is described as follows:

$$
q_{c}\left(z_{k}\right)= \begin{cases}q_{c, \text { top }}\left(z_{k}-z_{\text {bottom }}\right) /\left(z_{\text {top }}-z_{\text {bottom }}\right), & \left(z_{\text {bottom }}<z_{k}<z_{\text {top }}\right) \\ 0, & \left(z_{k}<z_{\text {bottom }} \text { or } \quad z_{k}>z_{\text {top }}\right)\end{cases}
$$

with $q_{c \text {,top }}=3.5 \times 10^{-4} \mathrm{~kg} \mathrm{~kg}^{-1}, z_{\text {top }}=2000 \mathrm{~m}, z_{\text {bottom }}=$ $1000 \mathrm{~m}$, and layer index $k$. In our numerical setting for the vertical layers, the cloud-top layer is located at $z=1853 \mathrm{~m}$. Other hydrometeors are assumed to be zero. Only in the initial conditions for NDW6, the cloud number concentration $n_{c}$ has a constant value of $n_{c}=25.0 \times 10^{6} \mathrm{~m}^{-3}$ through the cloud layer; the mean mass cloud-droplet radius $r_{c}$ has a value of approximately $15 \mu \mathrm{m}$ at the cloud top. On the other hand, in NSW6, the cloud water number concentration is assumed to be a time-invariant global constant $\left(n_{c}=50 \times 10^{6} \mathrm{~m}^{-3}\right)$. The atmospheric temperature $T_{a}$ is given as follows:

$$
T_{a}\left(z_{k}\right)= \begin{cases}T_{a, \mathrm{scc}}+\Gamma_{\mathrm{low}} z_{k}, & \left(z_{k} \leq z_{\mathrm{top}}\right) \\ \max \left[T_{a, \mathrm{scc}}+\Gamma_{\mathrm{low}} z_{\mathrm{top}}+\Gamma_{\mathrm{up}}\left(z-z_{\mathrm{top}}\right)+\delta T, T_{\min }\right], & \left(z_{k}>z_{\mathrm{top}}\right)\end{cases}
$$

with $T_{a, \text { sfc }}=275 \mathrm{~K}, T_{\min }=180 \mathrm{~K}, \delta T=5 \mathrm{~K}, \Gamma_{\text {low }}=$ $0.009 \mathrm{~K} \mathrm{~m}^{-1}$, and $\Gamma_{\text {up }}=0.005 \mathrm{~K} \mathrm{~m}^{-1}$. The atmospheric temperature above the cloud top $\left(z_{\text {top }}\right)$ actually does not have any impact on the simulation since the cloud layer does not exist as shown in Eq. (1). The cloud layer is supercooled when using the temperature profile. The relative humidity with respect to water $\mathrm{RH}_{w}$ is set to unity under the cloud top for simplicity $\left[\mathrm{RH}_{w}=1.0\left(z_{k} \leqq z_{\text {top }}\right)\right]$. On the other hand, the relative humidity with respect to ice $\mathrm{RH}_{i}$ is higher than unity in the cloud layer at atmospheric temperatures colder than $0^{\circ} \mathrm{C}$. Thus, cloud water starts to evaporate after ice particles are generated through ice cloud microphysics. The relative humidity with respect to ice $\mathrm{RH}_{i}$ is set to 0.8 above the cloud top to avoid initiation of cloud ice $\left[\mathrm{RH}_{i}=0.8\left(z_{k}>z_{\text {top }}\right)\right]$. The relative humidity below the cloud base does not have any impact on the supercooled liquid layer because the boundary layer processes are switched off in the single-column model. Surface pressure is $1000 \mathrm{hPa}$, and hydrostatic balance is assumed in the initial conditions.

The time step is set to $30 \mathrm{~s}$ to be consistent with the global simulations by Seiki et al. (2015a). Similarly, the single-column model has the same vertical layers as the global simulation:
40 vertical layers are located from the surface to the model top at 40-km altitude [see Table 1 in Satoh et al. (2010) for details]. No wind and no surface flux are assumed for simplicity. The prognostic variables (total air mass, moist internal energy, specific humidity, and prognostic variables used in cloud microphysics) are updated every time step as is done in NICAM.

\section{b. Cloud microphysics schemes}

NSW6 is a single-moment bulk cloud microphysics scheme based on Lin et al. (1983) and Rutledge and Hobbs (1983). Prognostic variables of NSW6 are the mixing ratios of water vapor, cloud water, rain, cloud ice, snow, and graupel $\left(q_{v}, q_{c}, q_{r}\right.$, $q_{i}, q_{s}$, and $q_{g}$, respectively). Tomita (2008) simplified the original scheme to reduce computational costs for the purpose of global cloud-system-resolving simulations. The scheme was evaluated and modified by comparisons to satellite observations (e.g., Satoh et al. 2010; Kodama et al. 2012; Hashino et al. 2013, 2016). Roh and Satoh (2014) revised mainly the particle size distributions of rain, snow, and graupel, and the particle shapes of snow. As a result, NSW6 could effectively capture the characteristic shape of the vertical profile of radar echoes by 
TRMM observations (Roh et al. 2017). This study used the latest version of NSW6 (Roh et al. 2017).

NDW6 is a double-moment bulk cloud microphysics scheme based on Seifert and Beheng (2001, 2006). The prognostic variables of NDW6 are the number concentrations of cloud water, rain, cloud ice, snow, and graupel $\left(n_{c}, n_{r}, n_{i}, n_{s}\right.$, and $n_{g}$, respectively) as well as the mixing ratios of vapor and hydrometeors $\left(q_{c}, q_{r}, q_{i}, q_{s}\right.$, and $\left.q_{g}\right)$. The scheme was optimized by reference to a spectral bin scheme (e.g., Seifert and Beheng 2001, 2006). Thus, the scheme was designed for general cloud systems. Seiki and Nakajima
(2014) implemented the scheme in the NICAM model with minor modifications and Seiki et al. (2014) improved the nonspherical modeling of ice hydrometeors to accurately calculate ice-cloud radiative forcing. Advances of NDW6 from the original scheme are summarized in Satoh et al. (2018). This study used the latest version of NDW6 (Seiki et al. 2015b).

In the single-column model, the heterogeneous ice nucleation parameterization for the condensation and deposition freezing modes used in NDW6 diagnoses the nucleated ice number concentration $n_{\text {het }}$ (P07) as follows:

$$
\begin{aligned}
n_{\text {het }} & = \begin{cases}10^{3} \exp \left[0.3 \times 12.96\left(S_{i}-0.1\right)\right], & \left(T_{a} \leq-30.0^{\circ} \mathrm{C}\right) \\
0.06 \times 10^{3} \exp \left[12.96\left(S_{i}-0.1\right)-0.639\right], & \left(0^{\circ} \mathrm{C} \leq T_{a}<-30.0^{\circ} \mathrm{C}\right)\end{cases} \\
n_{i} & =\max \left(n_{i}, n_{\text {het }}\right),
\end{aligned}
$$

where $S_{i}$ is the supersaturation with respect to ice. Note that the max function is specifically introduced for the single-column model. In low-level mixed-phase clouds, ice nucleation occurs near the cloud top and then cloud ice falls to the cloud bottom, where $n_{\text {het }}=0$. In this situation, $n_{i}$ should be larger than $n_{\text {het }}$ near the cloud bottom. In both cloud microphysics schemes, gravitational sedimentation was solved using a semi-Lagrangian scheme, which is conservative and positive definite (Xiao et al. 2003). Note that cloud water and cloud ice are assumed to not fall in NSW6 (Roh et al. 2017) whereas all hydrometeors are assumed to fall in NDW6. In the phase change, the atmospheric temperature changes so as to conserve the moist internal energy in the same manner as NICAM [see appendix b.3 in Satoh et al. (2008) for more detail].

\section{Results}

\section{a. Comparison of NSW6 to NDW6}

The time series of the mixing ratios of hydrometeors from NSW6 are shown in Fig. 5. Supercooled liquid water disappeared within only $15 \mathrm{~min}$ (approximately) after the initiation of the simulation. Correspondingly, ice hydrometeors grew, and then the cloud layer decayed with precipitation of snow and graupel. Melting ice particles form a thin liquid cloud layer near the sea surface because cloud water is assumed as a nonprecipitating hydrometeor in NSW6. In contrast, supercooled liquid water was maintained and the ice water content is negligibly small (at most $q_{i} \sim 4.0 \times 10^{-3}$ ) when using NDW6 (Fig. 6). Thus, the characteristics of liquid clouds in the global simulation (cf. Fig. 1) were reproduced in this single-column model.

First, we analyzed the budgets of the mixing ratios between the hydrometeors to find the key processes that cause the depletion of cloud water in NSW6. Table 1 summarizes the four largest-magnitude terms among all of the production/reduction processes at the cloud top at $t=2 \mathrm{~min}$. We found that cloud water was mostly reduced by collisional growth to rain droplets and by evaporation at the initial stage. Rain droplets efficiently rimed ice hydrometeors, and then, cloud water was further reduced by riming as the ice hydrometeors grew in later stages.
In contrast, the budget analysis for NDW6 at the cloud top at $t=$ 2 min showed that gravitational sedimentation was the major reduction term of cloud water of $\partial q_{c} / \partial t=-2.78 \times 10^{-8} \mathrm{~kg} \mathrm{~kg}^{-1} \mathrm{~s}^{-1}$ and that evaporation of cloud water of $\partial q_{c} / \partial t=-1.30 \times$ $10^{-9} \mathrm{~kg} \mathrm{~kg}^{-1} \mathrm{~s}^{-1}$ slowly balanced vapor deposition by cloud ice of $\partial q_{i} / \partial t=1.04 \times 10^{-9} \mathrm{~kg} \mathrm{~kg}^{-1} \mathrm{~s}^{-1}$. Hereinafter, we intensively examined autoconversion, accretion, evaporation, and riming processes.

NSW6 used the autoconversion and accretion parameterizations proposed by Berry (1968, hereinafter B68) following Lin et al. (1983). The B68 parameterizations were reported to overestimate the conversion from cloud water to rain compared to satellite observations (Suzuki et al. 2011, 2015). One may try to tune the coefficients used in the parameterizations to increase the lifetime of cloud water. However, Kotsuki et al. (2018) showed that the Berry's formulation cannot deal with precipitation efficiency and cloud radiative forcing at the same time, even when using a parameter optimization technique based on data assimilation. Similarly, the discrepancies between microphysical validity and cloud feedbacks were recognized in other autoconversion schemes for several CMIP5 GCMs (e.g., Golaz et al. 2013; Suzuki et al. 2013, 2015).

To solve this issue, we replaced the autoconversion and accretion parameterizations with the ones proposed by Khairoutdinov and Kogan (2000, hereinafter KK00). The parameterizations are widely used in cloud microphysics schemes for GCMs or CRMs (e.g., Morrison and Gettelman 2008). In addition, Suzuki et al. (2015) showed that the KK00 parameterizations effectively simulated a broad range of radar echoes profiles observed by the MODIS and CloudSat satellites. Therefore, we expect that the KK00 parameterizations are applicable to NSW6 in terms of global simulations. The KK parameterizations were implemented in NSW6 by Sato et al. (2015) and were found to be comparable the autoconversion and accretion parameterizations used in NDW6 (Seifert and Beheng, 2001, 2006) in the Rain in Cumulus over the Ocean (RICO) case (vanZanten et al. 2011). The detailed formula of the autoconversion and accretion parameterizations are given in appendix $\mathrm{A}$. 

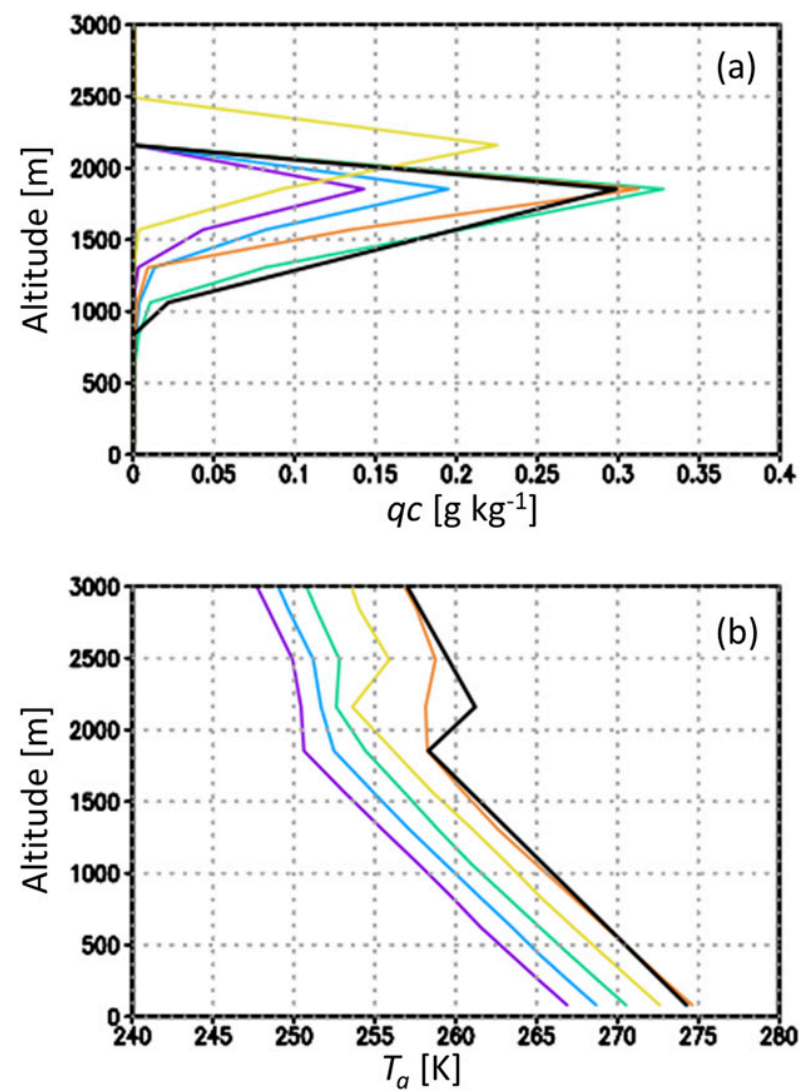

FIG. 4. The vertical profiles of (a) atmospheric temperature (K), and (b) mixing ratio of cloud water $\left(\mathrm{g} \mathrm{kg}^{-1}\right)$. The various colored lines show sample profiles derived at $105^{\circ} \mathrm{E}$ and $60^{\circ} \mathrm{S}$ (orange), $58^{\circ} \mathrm{S}$ (yellow), $56^{\circ} \mathrm{S}$ (green), $54^{\circ} \mathrm{S}$ (blue), and $52^{\circ} \mathrm{S}$ (purple) at $0600 \mathrm{UTC}$ 1 Jun 2004 from the global simulation with NDW6. The black lines show the simplified vertical profile for the initial conditions of the single-column model.

In NSW6, the evaporation rates of cloud water were almost balanced with the sum of vapor depositions of ice hydrometeors. This phenomenon is widely known as the Bergeron-Findeisen process: ice hydrometeors consume surrounding liquid droplets due to the difference in the saturated vapor pressure between the ice and liquid phases. The Bergeron-Findeisen process should also occur in NDW6 but was actually not effective (Figs. 6a,c).

Figure 7 shows the comparison of the time scales of vapor deposition growth between the NSW6 and NDW6 simulations at $t=2 \mathrm{~min}$. The time scale is defined by the characteristic time to consume the ice supersaturation in vapor deposition [see Eq. (B3) in appendix B]. Vapor deposition occurred too quickly in NSW6 (a few hours around the cloud top), whereas NDW6 captured slower growth rates of 10 days, thereby prolonging supercooled liquid water. Consequently, in NSW6, greater evaporation of cloud water compensated for the rapid vapor deposition onto ice hydrometeors (Table 1); that is, the Bergeron-Findeisen process dominated.

In theory, the growth rate of vapor deposition is proportional to the number concentration and mean diameter (maximum dimension in the case of nonspherical particles) of hydrometeors for a given environmental condition (see appendix B). Figure 8 shows a comparison of the number concentrations of ice hydrometeors between the two schemes. We found that $n_{i}, n_{s}$, and $n_{g}$ from the NSW6 simulation are too high in terms of low-level mixed-phase clouds whereas those from the NDW6 simulation fall within typical ranges of observations (described in the next paragraph). The particle diameter did not vary greatly between the NSW6 and NDW6 simulations (not shown). The bias in the diagnosis of the number concentration results in rapid growth of cloud ice. In the same manner, vapor deposition by snow and graupel were overestimated because of the bias in the number concentrations (Table 1). In addition, heavy riming in the NSW6 simulation (Table 1) also originated from the bias in the diagnosed number concentrations because the riming growth rate is approximately proportional to the number concentrations and to the second to third power of the mean diameter (maximum dimension) (appendix C).

The ice number concentration values in low-level mixedphase clouds have been estimated by observations ships (e.g., Bigg 1973) and in situ aircraft measurement campaigns (e.g., McFarquhar et al. 2011; Jackson et al. 2012; Grosvenor et al. 2012; Chubb et al. 2013; Mioche et al. 2017). The values are typically $0.01-1.0 \mathrm{~L}^{-1}$ around the $270-260 \mathrm{~K}$ temperature range over the Southern Ocean and the Antarctic coast (Grosvenor et al. 2012; Chubb et al. 2013) although the values are highly variable, ranging from $10^{-4}$ to $10 \mathrm{~L}^{-1}$, depending on the atmospheric temperature and aerosol conditions.

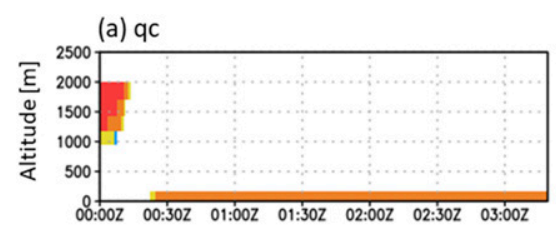

(c) qi

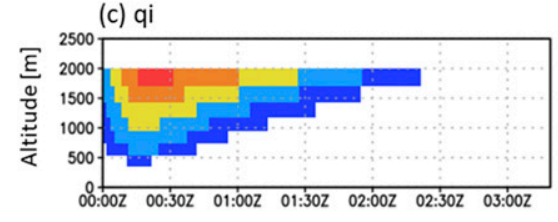

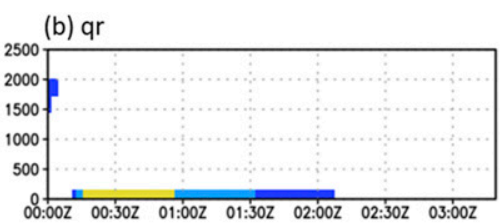

(d) qs

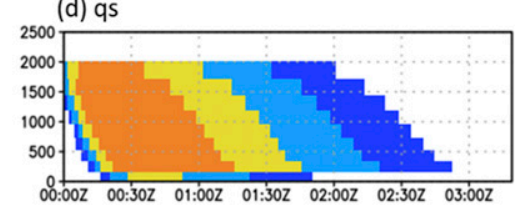

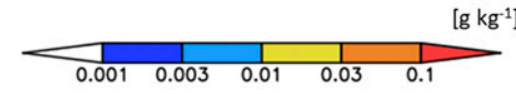

(e) $9 \mathrm{~g}$

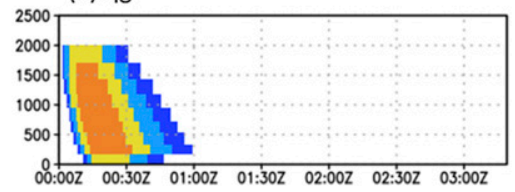

FIG. 5. Time series of (a) $q_{c}$, (b) $q_{r}$, (c) $q_{i}$, (d) $q_{s}$, and (e) $q_{g}\left(\mathrm{~g} \mathrm{~kg}^{-1}\right)$ from the single-column simulation with NSW6. 
(a) qc

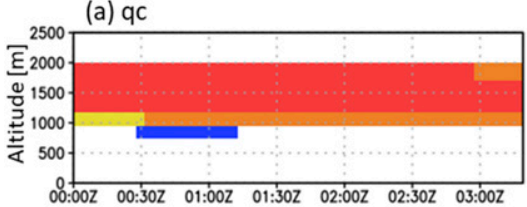

(c) qi

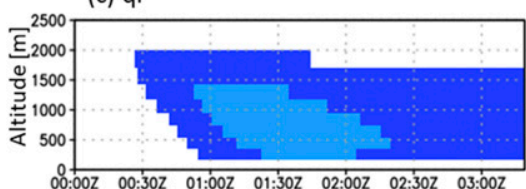

(b) qr

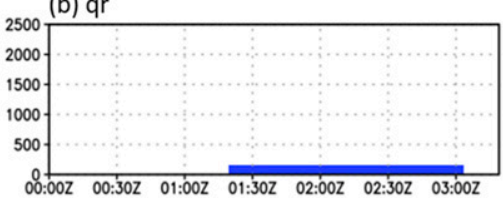

(d) qs

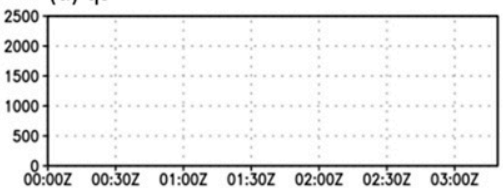

FIG. 6. As in Fig. 5, but with NDW6.

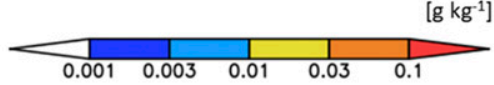

(e) $\mathrm{qg}$

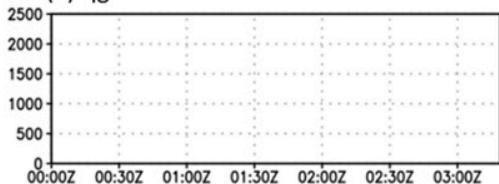

Vergara-Temprado et al. (2018) indicated that low-level clouds over the Southern Ocean are characterized by lower population of ice nuclei than those over continental regions and the northern midlatitude oceans. Therefore, $n_{i}$ values simulated in NDW6 (approximately $0.4 \mathrm{~L}^{-1}$ at the cloud top) are reasonable.

NSW6 (Roh and Satoh 2014) used the diagnosis of $n_{i}$ based on Hong et al. (2004). He combined the mass-weighted mean terminal velocity of cloud ice proposed by Heymsfield and Donner (1990, hereinafter HD90) with the mass-diameter relationship of ice crystals observed by Heymsfield and Iaquinta (2000), and derived the following expression:

$$
n_{i}=c\left(\rho_{a} q_{i}\right)^{d}
$$

where a fitting coefficient $c$ and an exponent $d$ for various shape of ice crystals were used. Roh and Satoh (2014) assumed the shape of cloud ice as a single bullet and used the values $c=$ $5.38 \times 10^{7}$ and $d=0.75$ (here, $n_{i}$ has units of inverse meters cubed). Technically, Roh and Satoh (2014) used Eq. (4) with upper and lower limiting values of mixing ratio and number concentration as $n_{i}=\min \left(\max \left\{c\left[\max \left(\rho_{a} q_{i}, 10^{-16}\right){ }^{d}\right], 10^{3}\right\}, 10^{6}\right)$. As a result, $n_{i}$ has the lower limit value of $10^{3} \mathrm{~m}^{-3}\left(=1 \mathrm{~L}^{-1}\right)$ regardless of conditions (see Fig. 8). Diagnosed $n_{i}$ values from Eq. (4) are unrealistically high relative to the typical $n_{i}$ values over the Southern Ocean as mentioned above, and, hence, vapor deposition is always overestimated in the low-level mixed-phase cloud system.

NDW6 uses the parameterization for heterogeneous ice nucleation proposed by $\mathrm{P} 07$ as described in section $2 \mathrm{~b}$. We tried the same heterogeneous ice nucleation parameterization as NDW6 [Eq. (3)] for NSW6 as well. A decrease in $n_{i}$ by replacing a heterogeneous ice nucleation scheme is expected to suppress consumption of supercooled liquid water as was shown in Forbes and Ahlgrimm (2014). We set a fixed lower limit value of $n_{i}=10^{-3} \mathrm{~m}^{-3}$ for practical use in NSW6 when the atmospheric temperature is warmer than $0^{\circ} \mathrm{C}$.

In general, $n_{i}$ values are diagnosed using the environmental conditions to calculate vapor deposition in single-moment bulk cloud microphysics schemes under the condition with $q_{i}=0$ and $S_{i}>0$. This means that nonphysical values of $n_{i}$ are necessarily assumed outside cloud layers if $n_{i}$ values are diagnosed only by the atmospheric temperature or determined by a lower limit [see Eq. (4) with the min and max functions]. In contrast, the values are negligibly small outside the cloud layers with the new formulation because the values strongly depend on $S_{i}$ [see Eq. (3)]. Therefore, the change in the diagnosis of $n_{i}$ effectively inhibits artificial vapor deposition at the initiation of ice hydrometeors in the low-level mixed-phase clouds.

When using NDW6, cloud ice falls to the cloud bottom after the initiation. Thus, major portions of cloud ice departed from a major portion of the cloud water by gravitational sedimentation. This mechanism is considered to be essential to maintain a supercooled liquid layer. Since NSW6 does not assume cloud water and cloud ice as precipitating hydrometeors (terminal velocities are set to zero), major portions of cloud water and cloud ice concentrate together near the cloud top (Figs. 5a,c). As a result, $q_{c}$ is efficiently consumed by cloud ice. NSW6 originally assumed cloud ice as a precipitating hydrometeor (e.g., Kodama et al. 2012) and thus, we recover the setting and use a parameterization for the terminal velocity of cloud ice proposed by HD90.

\section{b. Sensitivity experiments using NSW6}

We tested a number of sensitivity experiments step by step and found that improvements in supercooled liquid water simulations could not be achieved by any single modification. As shown in the previous subsection, autoconversion, accretion, ice nucleation, and the terminal velocity of cloud ice should be revised first because they are involved with the largest reduction rates of supercooled liquid water. Thus, we show improvements in supercooled liquid water by sequentially modifying cloud microphysical processes in NSW6. The series of sensitivity experiments is summarized in Table 2 .

\section{1) SENSITIVITY OF AUTOCONVERSION OF CLOUD WATER AND TERMINAL VELOCITY OF CLOUD ICE}

Figure 9 shows the time series of the mixing ratios of each hydrometeor category in the EXPaut experiment, which uses NSW6 with the revised version of the parameterizations for autoconversion, accretion, and terminal velocity of cloud ice. The changes in the autoconversion and accretion parameterizations result in significant reductions in rain production down to approximately one-tenth of the original values at $t=2 \mathrm{~min}$. This effect slightly prolongs the lifetime of $q_{c}$ but is not yet sufficient. The mixing ratios of cloud ice, snow, and graupel remain high even a few minutes after the initial conditions. 


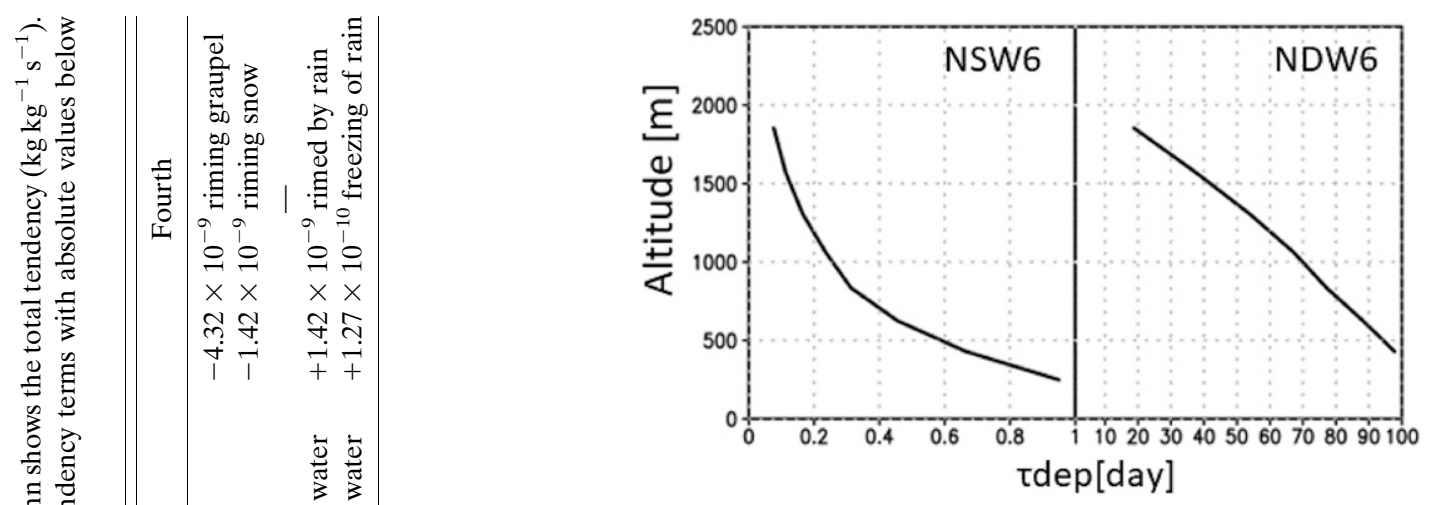

FIG. 7. Vertical profiles of the time scale (day) of vapor deposition by cloud ice at $t=2 \mathrm{~min}$ from the single-column simulations with (left) NSW6 and (right) NDW6.

\section{2) Sensitivity of Heterogeneous ice NUCleation}

We performed a new experiment EXPnuc, which is the same as the EXPaut experiment but with the revised ice nucleation parameterization [Eq. (3)]. Again, the time series of the mixing ratios is shown in Fig. 10. The change in $n_{i}$ diagnosis significantly reduces $q_{i}$, but $q_{c}$ is not yet improved. Budget analysis shows that $q_{s}$ is initiated by autoconversion of cloud ice and $q_{g}$ is initiated by freezing of rain (cf. Table 1). After the initiation, snow and graupel with even very small values of $q_{s}$ and $q_{g}$ grow rapidly through vapor deposition and riming because of their high number concentrations (not shown).

Figure 11 shows the relationships between the mixing ratio and diagnosed number concentrations through the cloud layer at time steps from 0 to $2 \mathrm{~min}$ from the EXPnuc experiment. The ice number concentration decreases to less than one tenth of the old version of the diagnosed values. Interestingly, given a mixing ratio value, $n_{g}$ is largest and $n_{i}$ is smallest in NSW6. In general, rain and cloud ice are precursors of graupel and snow, respectively. Therefore, $n_{g}$ and $n_{s}$ should not be larger than $n_{r}$ and $n_{i}$. Based on these diagnoses, $n_{g}$ and $n_{s}$ spuriously increase after hydrometeor categories changes.

Discrepancies in the diagnoses of the number concentrations are a common issue for all single-moment bulk schemes. For example, the number concentrations of hydrometeors should not increase in vapor deposition, riming, but only the mixing ratios increase. Similarly, the total number concentrations should be conserved during freezing of supercooled liquid water. As a result, the number concentrations increase with increases in the mixing ratios when a single-moment bulk scheme diagnose the number concentration using the mixing ratio, e.g., assuming the Marshall-Palmer distribution for the particle size distributions. Spuriously increased $n_{i}, n_{s}$, and $n_{g}$ through depositional and riming growth further overestimate the growth rates as positive feedback and, consequently, supercooled liquid water rapidly disappears (Fig. 10). In the following subsections, we aim to alleviate the bias in the supercooled liquid water when using single-moment bulk schemes although it is not possible to fundamentally resolve this issue. 
(a) ni from NDW6

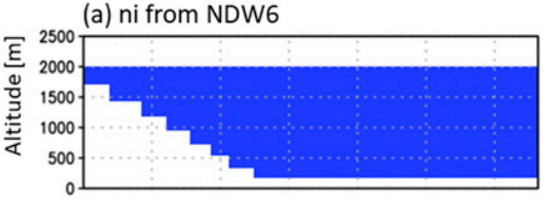

(d) ni from NSW6-ROH

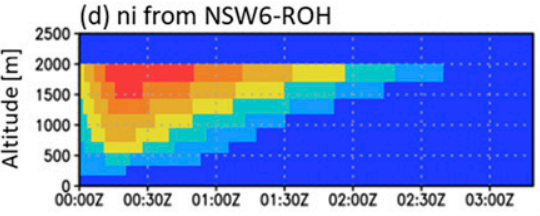

(b) ns from NDW6

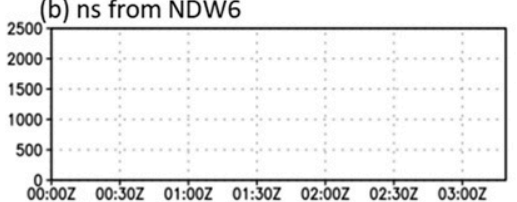

(e) ns from NSW6-ROH

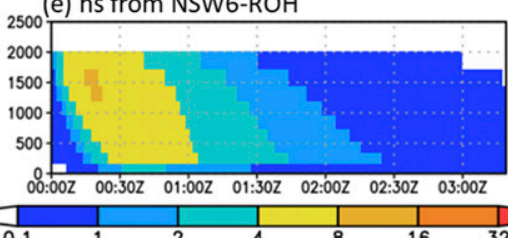

(c) ng from NDW6

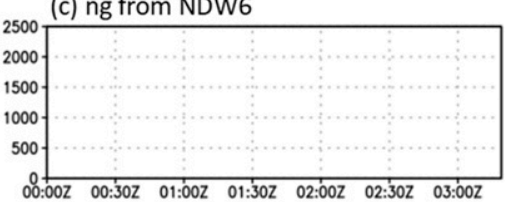

2500 (f) ng from NSW6-ROH

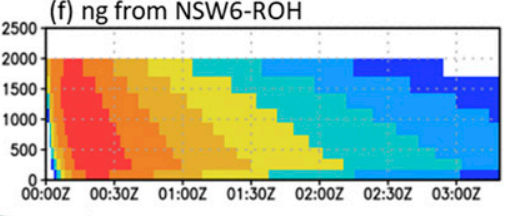

FIG. 8. (a)-(c) The predicted number concentrations of each ice hydrometeor category $\left(\mathrm{L}^{-1}\right)$ from the single-column simulation with NDW6, and (d)-(f) the diagnosed number concentrations for each ice hydrometeor category $\left(\mathrm{L}^{-1}\right)$ from the single-column simulation with NSW6.

\section{3) SENSITIVITY OF DEPOSITIONAL GROWTH}

The origin of the Bergeron-Findeisen process is evaporation of cloud water and vapor deposition onto ice particles. In NSW6, condensation/evaporation and vapor deposition/sublimation are explicitly calculated. In addition, the parameterization for the Bergeron-Findeisen process is calculated. Therefore, first, this study omits the latter parameterization for the BergeronFindeisen process used in NSW6 to avoid duplication.

This study suppresses the overestimated vapor deposition of snow and graupel using the following thresholds:

$$
\begin{aligned}
& \left(\frac{\partial q_{s}}{\partial t}\right)_{\text {dep }}=0, \quad \text { if } \quad\left(q_{s}<10^{-6} \quad \text { or } \quad q_{c}>10^{-6}\right) \text { and } \\
& \left(\frac{\partial q_{g}}{\partial t}\right)_{\text {dep }}=0, \quad \text { if } \quad\left(q_{g}<10^{-6} \text { or } q_{c}>10^{-6}\right) .
\end{aligned}
$$

These conditions are based on the fact that snow and graupel are initiated by collision and that snow and graupel play minor roles in the Bergeron-Findeisen process (conversion of mixing ratios between liquid and ice hydrometeors), especially at the initial stage of ice growth.

The issue in the original depositional growth terms is as follows:

$$
\begin{aligned}
\left(\frac{\partial q_{j}}{\partial t}\right)_{\text {dep }, j} \propto & \max \left[\min \left(\bar{D}_{j}, \bar{D}_{j, \text { max }}\right), \bar{D}_{j, \min }\right] \\
& \times \max \left[\min \left(n_{j}, n_{j, \text { max }}\right), n_{j, \min }\right] S_{i},
\end{aligned}
$$

where $\bar{D}_{i}$ is the mean mass diameter and subscripts min and max indicate the minimum and maximum values. The max and min functions are used for avoiding numerical errors with keeping the computational performance on supercomputers. Derivation of the equation is omitted here and the original paper (Tomita 2008) should be referred to for detail. Thus, the vapor deposition term has large values with the lower limit values of $n$ and $\bar{D}$ even when the mixing ratios of snow and graupel are zero and, subsequently, large $n_{s}$ and $n_{g}$ values are diagnosed from the overestimated mixing ratios. Thus, artificial nucleation of snow and graupel occurs unless the vapor deposition is switched off. Note that the threshold of
$10^{-6} \mathrm{~kg} \mathrm{~kg}^{-1}$ is chosen as a negligibly small value by reference to the detectable minimum limit of CloudSat (e.g., Austin et al. 2009).

Past GCM studies pointed out that the Bergeron-Findeisen process controls the liquid-ice portioning in the mixed-phase clouds and, hence, suppression of the Bergeron-Findeisen process results in an increase in supercooled liquid water (Forbes and Ahlgrimm 2014; Kay et al. 2016; Tan and Storelvmo 2016; Kawai et al. 2019). Our method is different from the ones for GCMs but suppression of vapor deposition works in the same way.

The lifetime of supercooled liquid water is significantly prolonged by the conditions used (Fig. 12). Snow is no longer overestimated by the threshold for vapor deposition. However, relative to NDW6, phase change occurs early in the lower part of the supercooled liquid cloud layer. The growth rate of $q_{g}$ through riming is still overestimated since the diagnosed values of $n_{g}$ are artificially high.

\section{4) Sensitivity OF RIMING GROWTH}

We performed a sensitivity experiment, EXPcutoff, that suppressed the riming process. Many observational studies

TABLE 2. Brief summary of the numerical settings for the sensitivity experiments.

\begin{tabular}{ll}
\hline Name of expt & \multicolumn{1}{c}{ Numerical settings } \\
\hline NSW6 & Roh and Satoh (2014) and Roh et al. (2017) \\
EXPaut & $\begin{array}{r}\text { The same as NSW6 but with the KK00 } \\
\text { parameterization for autoconversion and } \\
\text { accretion and the HD90 parameterization } \\
\text { for terminal velocity of cloud ice }\end{array}$ \\
The same as EXPaut but with the P07 \\
parameterization for heterogeneous ice \\
nucleation \\
The same as EXPnuc but with the threshold of \\
mixing ratio of snow and graupel for vapor \\
deposition \\
The same as EXPdep but with the threshold of \\
mean diameter of snow and graupel for \\
riming based on Wang (2002)
\end{tabular}



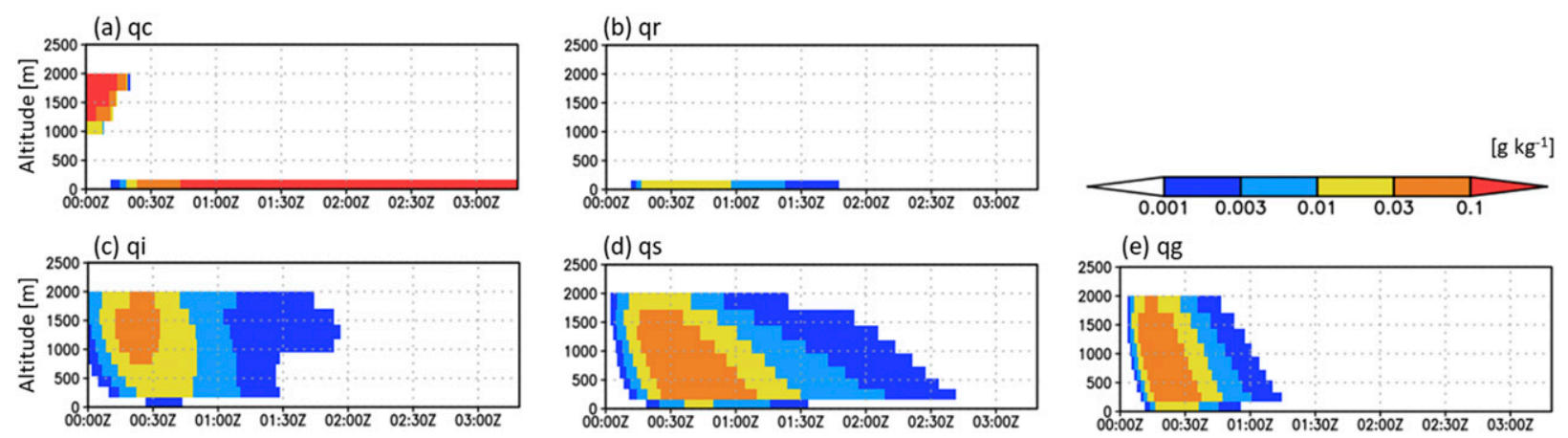

FIG. 9. As in Fig. 5, but from the EXPaut experiment.

(e.g., Ono 1969; Harimaya 1975; Reinking 1979) have revealed the existence of a cutoff diameter of ice crystals $d_{\text {cutoff }}$ below which rimed ice particles were not observed. Böhm (1992) started from a theoretical expression of the riming process and explained that the collision efficiency between cloud droplets and ice particles should not be zero but was negligible when the ice particle diameter was smaller than the cutoff diameter. In addition, the cutoff diameter varies by ice species (shapes). Similar results were also given by Wang (2002), who numerically calculated collisional process between ice particles and liquid droplets.

This study chose $d_{\text {cutoff }}=150 \mu \mathrm{m}$ for both graupel and snow particles as was used in NDW6 following Seifert and Beheng (2006). Riming growth is switched off when the mean diameter is smaller than the cutoff diameter. Here, the mean diameter is calculated by integrating the particle size distribution function. Similarly, Furtado and Field (2017) used a threshold of ice mixing ratio to suppress riming growth in their single-moment bulk cloud microphysics scheme and successfully increased liquid water content in low-level mixed-phase clouds. Note that the cutoff diameter for cloud ice is neglected in this study.

By using the cutoff diameter, supercooled cloud water is sustained in the NSW6 simulation (Fig. 13). Inhibition of graupel growth slightly increases snow amounts, but the cloud layer is completely comparable between the NSW6 and NDW6 simulations (see Fig. 6a). The mixing ratio thresholds for vapor deposition [Eqs. (5) and (6)] result in small $n_{s}$ and $n_{g}$ values (Figs. 14a,b), and consequently, the mean diameters of snow $\left(d_{s}\right)$ and graupel $\left(d_{g}\right)$ fall below the cutoff diameter (Figs. 14c,d).

\section{c. Sensitivity to atmospheric temperature}

Low-level mixed-phase clouds are widely distributed in the polar regions (cf. Fig. 3). Here, we performed additional sensitivity experiments with two different atmospheric temperature profiles by setting $T_{a \text {,sfc }}=270$ and $265 \mathrm{~K}$ in Eq. (2). In this comparison, the NSW6 scheme used the EXPcutoff settings (see Table 2).

Figure 15 shows a comparison of the time series of $q_{c}, q_{i}$, and $n_{i}$ at the cloud top $(z=1853 \mathrm{~m})$ for the various atmospheric temperature settings. We can see that the lifetime of cloud water is shorter in the NDW6 simulation than in the NSW6 simulation under the three environmental conditions. In particular, the differences between the two schemes becomes large as the environmental atmospheric temperature decreases. Correspondingly, cloud ice mixing ratio increases in the NDW6 simulation. From budget analyses (not shown) in the NDW6 simulation with $T_{a, \mathrm{sfc}}=$ $265 \mathrm{~K}$, heterogeneous freezing of supercooled liquid water first dominates the production of $q_{i}$ and then vapor deposition substantially increases $q_{i}$. The supercooled liquid layer collapses after cloud ice develops in the NDW6 simulation. In contrast, in the NSW6 with $T_{a \text {,sfc }}=265 \mathrm{~K}$, cloud ice mixing ratio does not sufficiently grow through vapor deposition because $n_{i}$ values in NSW6 are approximately one
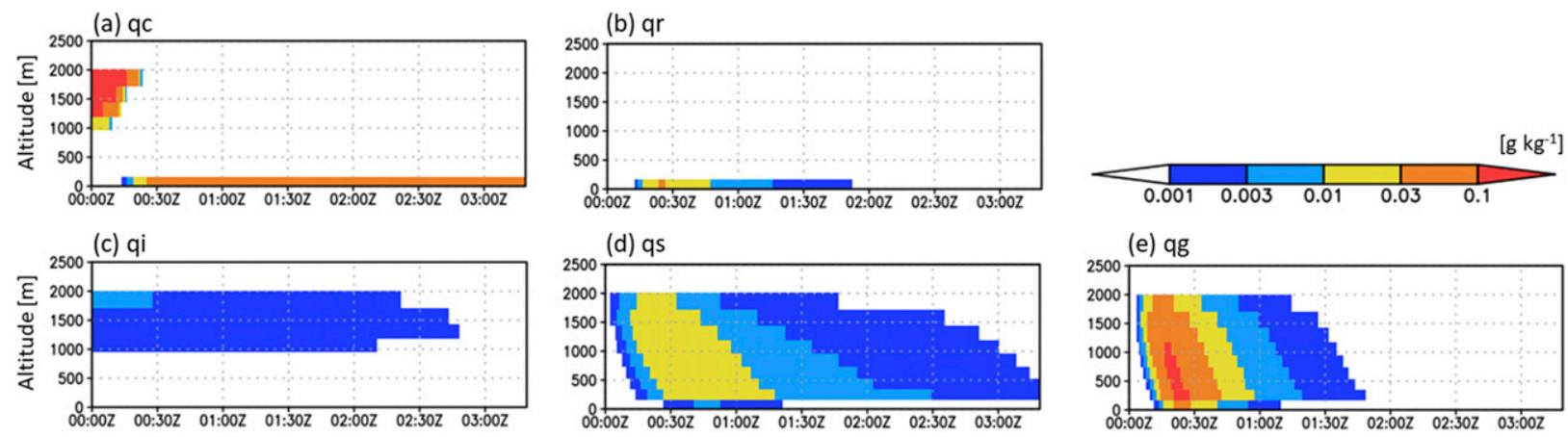

FIG. 10. As in Fig. 5, but from the EXPnuc experiment. 


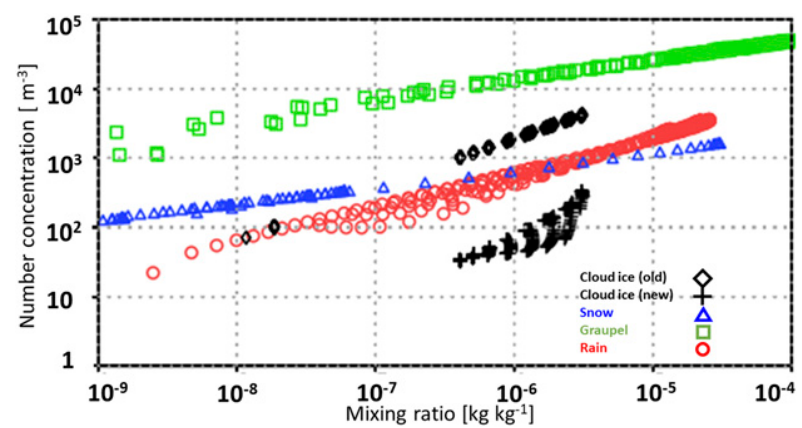

FIG. 11. Relationships between the mixing ratio and diagnosed number concentrations used for cloud ice (old: black diamonds; new: black plus signs), snow (blue triangles), graupel (green squares), and rain (red circles). The points are plotted through the cloud layer at time steps from 0 to $2 \mathrm{~min}$.

to two orders of magnitude smaller than $n_{i}$ values in NDW6 (Fig. 15c and cf. appendix B).

The issue in the different sensitivity of the cloud lifetime to the atmospheric temperature originates from the production of $n_{i}$ through heterogeneous freezing. Both NDW6 and NSW6 used a parameterization proposed by Bigg (1953). This parameterization assumes that the probability of freezing originates from the population of ice nucleating particles in liquid droplets and, hence, the production of $n_{i}$ is proportional to $n_{c}$ with the upper limit of $n_{c}$. Here, the typical range of $n_{c}$ $\left(10^{7}-10^{8} \mathrm{~m}^{-3}\right)$ is much higher than the typical range of ice nuclei number concentration assumed in the heterogeneous ice nucleation scheme, especially over the Southern Ocean (0.1-10 $\mathrm{m}^{4} \mathrm{~m}^{-3}$; cf. section $\left.3 \mathrm{a}\right)$. Thus, heterogeneous freezing dominates the production of $n_{i}$ at the colder atmospheric temperature ranges. Therefore, it is difficult for single-moment bulk cloud microphysics schemes to capture the transition of lifetime of low-level mixed-phase clouds from the midlatitudes to polar regions. The NSW6 scheme revised in this study represents long-lived low-level mixed-phase clouds even in the colder temperature ranges.

\section{Discussion}

\section{a. Bias in the number concentrations}

Single-moment bulk cloud microphysics scheme do not predict the number concentrations and, hence, the diagnoses of the number concentrations and mean diameters of hydrometeor categories are not possibly optimized for various types of cloud systems. As a result, growth rates are potentially biased through their dependence on the number concentration and mean diameter (cf. appendix B and appendix C). NSW6 was optimized for reproducing deep convective cloud systems over the tropics and the midlatitudes compared to satellite observations (Roh et al. 2017). Low-level mixed-phase clouds, which are maintained by totally different processes from convective clouds, are just the case in which NSW6 had the large biases in cloud fraction and cloud radiative forcing.

This study alleviated the supercooled liquid water bias not by tuning but by updating cloud microphysical parameterizations and by introducing thresholds to avoid unreasonable growth of snow and graupel. However, the diagnosis of the number concentrations still remains incomplete in terms of global simulations. Figure 11 clearly indicates that the number concentrations of snow and graupel are unreasonably high compared to the number concentrations of cloud ice and rain. This kind of inconsistency among the number concentrations of hydrometeor categories generally originates from different references of particle size distribution (PSD) observations for each hydrometeor category.

NSW6 (Roh et al. 2017) refers to Rutledge and Hobbs (1983) for the PSDs of rain, DeMott et al. (2003) and P07 for the PSDs of cloud ice, Field et al. (2005) and Thompson et al. (2008) for the PSDs of snow, and Knight et al. (1982) for the PSDs of graupel. Target cloud systems and their environmental conditions differ among these studies. As a result, e.g., the background of graupel that is produced by freezing of rain happens to be different from the background of rain and does not match some simulation cases. This issue newly arises in global cloud-resolving simulations by highresolution GCMs because the GCMs necessarily simulate any type of cloud system with a single numerical setting in contrast to regional models.

Note that prediction of the number concentration has also uncertainties even using double-moment bulk cloud microphysics schemes or spectral bin cloud microphysics schemes. For example, the heterogeneous ice nucleation scheme used in this study implicitly assumes the background ice nuclei concentration. Thus, predicted number concentration should be carefully verified with observations at the same time.

\section{b. Toward alleviating the bias in the number concentration}

One can further alleviate the issue in the number diagnoses by using different assumptions for different cloud systems. For example, training data can be derived from double-moment bulk cloud microphysics schemes as used in this study or from satellite observations. Kotsuki et al. (2018) successfully optimized an uncertain time-invariant parameter (coefficient of the time scale of autoconversion) in cloud microphysics by data
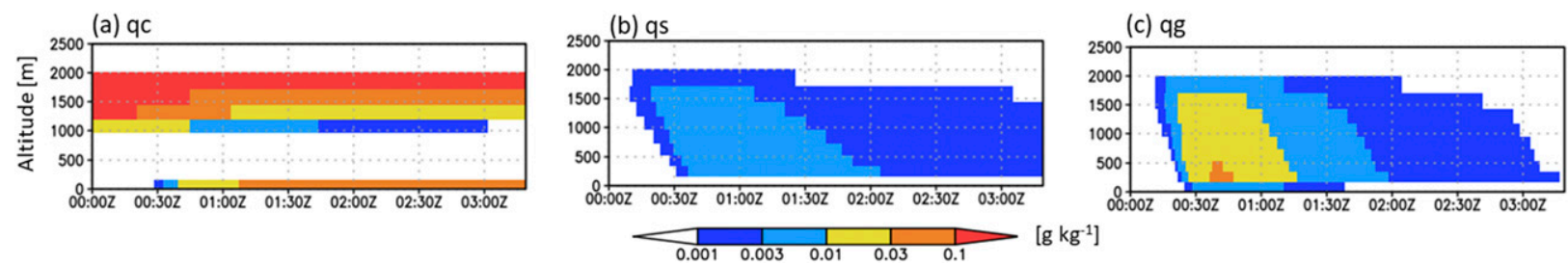

FIG. 12. Similar to Fig. 5, but only $q_{c}, q_{s}$, and $q_{g}$ from the EXPdep experiment are shown. 

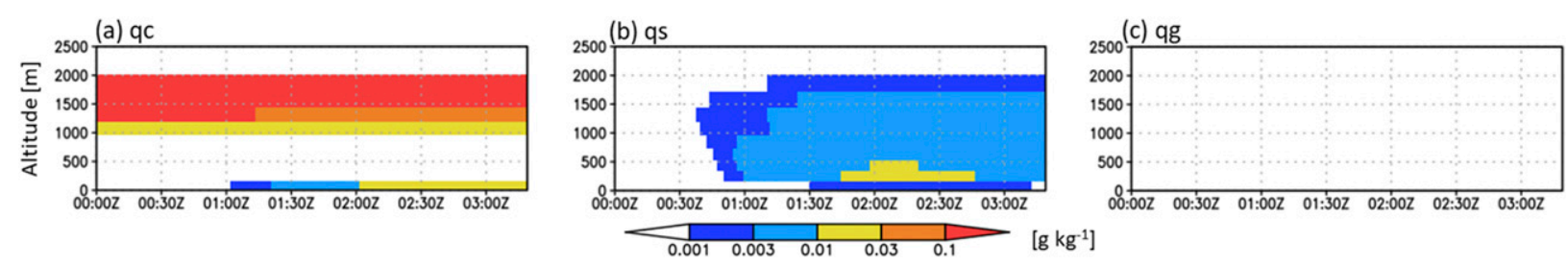

FIG. 13. As in Fig. 12, but from the EXPcutoff experiment.

assimilation using a multisatellite precipitation product. They suggested that the technique can be easily extended to diagnose the spatial distribution of such parameters, which means that the technique implicitly assumes spatial variability of cloud systems.

\section{c. Effects to other cloud systems}

This study only focuses on supercooled liquid water simulations of low-level mixed-phase clouds. On the other hand, the revision of NSW6 does affect other cloud systems. Specifically, replacement of autoconversion and accretion parameterizations globally changes cloud water distribution. It is known that multiple combinations of parameters used in various physical processes in GCMs should be optimized to achieve the radiative balance after changing autoconversion formulation (e.g., Golaz et al. 2013). In this study, lifetime of cloud water simulated with NSW6 is generally prolonged using the KK00 parameterizations (e.g., Sato et al. 2015). Therefore, it is expected that use of the EXPcutoff setting for global simulations results in, e.g., overestimation of ice clouds in convective regions due to oversupply of liquid water above the freezing level because empirical parameters used for ice cloud microphysics in NSW6 are optimized with the basic version of the autoconversion and accretion parameterizations (Kodama et al. 2012). Ice cloud microphysics in NSW6 with the EXPcutoff setting are to be revised as a next step.

\section{Summary}

In past NICAM simulations, the underestimation bias in mixed-phase low-level clouds over the Southern Ocean mainly originated from ice microphysics. A single-column model enabled simple and rapid evaluation of ice-cloud microphysics for various combinations of numerical schemes. The budget analysis for the single-moment bulk cloud microphysics scheme (NSW6) indicated that the excessive action of the Bergeron-Findeisen process and the subsequent occurrence of riming crucially reduced supercooled liquid water. NSW6 was improved by reference to the doublemoment bulk cloud microphysics scheme (NDW6).

The most important strategy is to suppress production of cloud ice, snow, and graupel in cloud layers. The following changes to the NSW6 scheme drastically increased the lifetime of the liquid cloud layer under supercooled conditions. The autoconversion and accretion schemes (B68) were replaced by recent ones (KK00). A diagnosis method of ice number concentration that was only a function of cloud ice mass concentration (Hong et al. 2004) was replaced by a heterogeneous ice nucleation scheme that was a function of temperature and of ice supersaturation (P07). Vapor deposition by snow and graupel was switched off when their mixing ratios were smaller than a certain threshold because vapor deposition worked without their mixing ratios (number concentrations) in NSW6. A cutoff diameter was used for riming. The cutoff diameter is

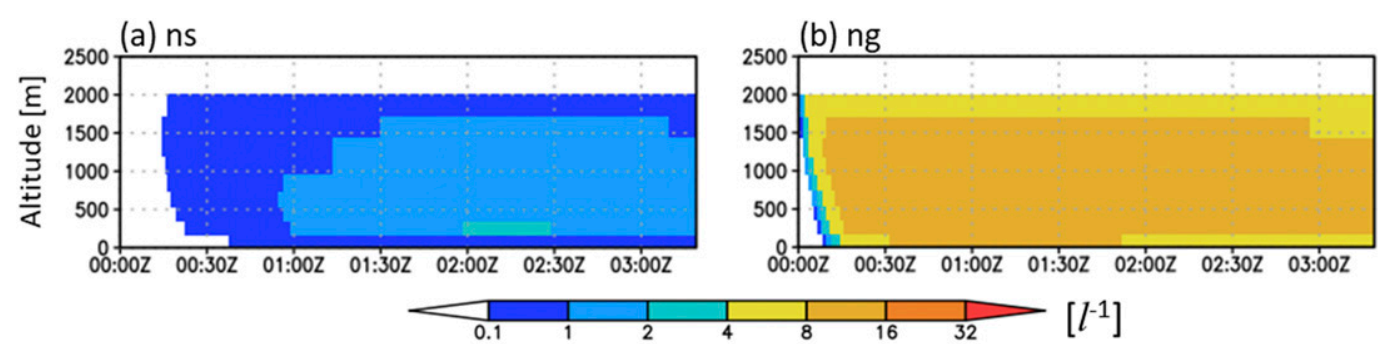

(c) ds

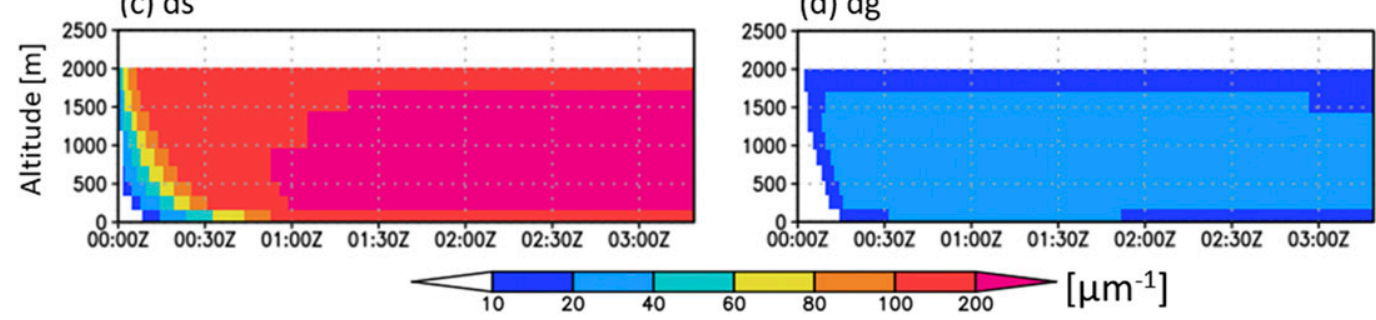

FIG. 14. The (a),(b) number concentrations and (c),(d) mean maximum dimensions of (left) snow and (right) graupel from the EXPcutoff experiment. 
(a)
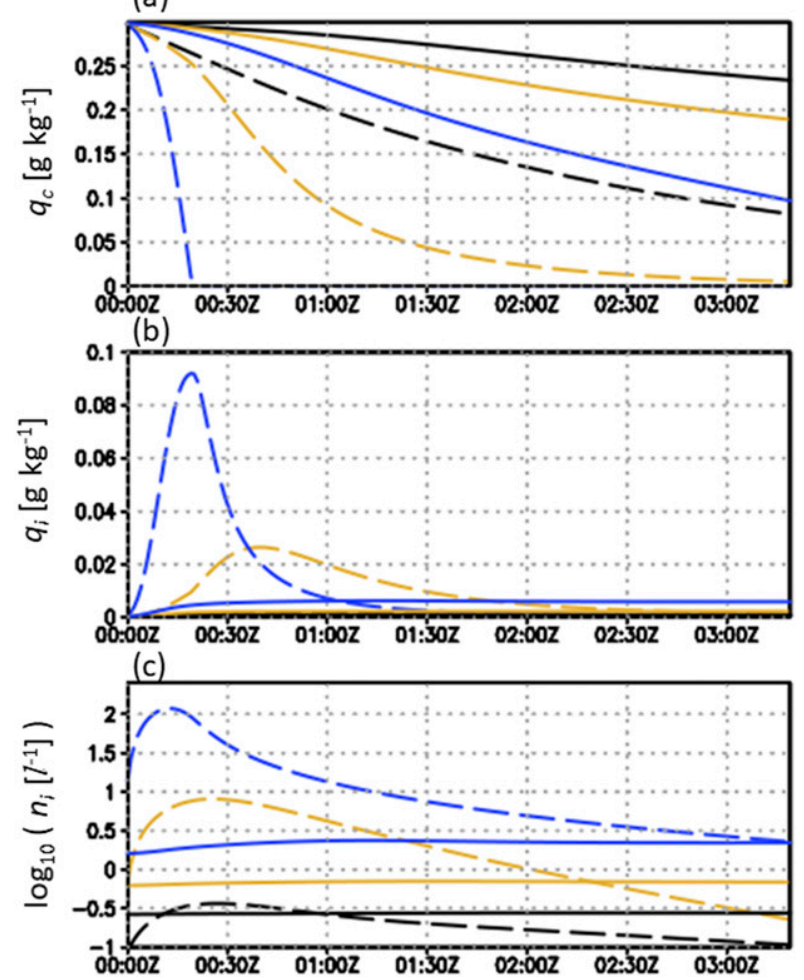

FIG. 15. Time series of (a) cloud water mixing ratio, (b) cloud ice mass concentration, and (c) cloud ice number concentration at the cloud top $(z=1853 \mathrm{~m})$. The solid lines indicate the single-column simulation with NSW6 with the EXPcutoff setting, and dashed lines indicate the single-column simulation with NDW6. Simulations with $T_{a \text {,sfc }}=275,270,265 \mathrm{~K}$ are presented by black, yellow, and blue lines, respectively.

validated by the past experimental data that collision efficiency is notably small for smaller ice particles. These changes are summarized in Table 2.

A fundamental issue remains in NSW6: diagnosis of number concentrations. The issue should commonly arise in low-level mixed-phase clouds simulated by any single-moment bulk cloud microphysics schemes. A double-moment bulk cloud microphysics scheme worked well to alleviate the bias in this study. Similarly, such double-moment bulk cloud microphysics schemes can also be a reference for the diagnosis of number concentrations in various cases of numerical simulations.

Acknowledgments. The satellite product MAC-LWP (maclwp_totallwpave_<year>_v1.nc4) was downloaded from the Goddard Earth Sciences Data and Information Services Center (GES DISC; current hosting: http://disc.gsfc.nasa.gov). Author T. Seiki was supported by the Integrated Research Program for Advancing Climate Models (TOUGOU) Grant JPMXD0717935457 from the Ministry of Education, Culture, Sports, Science and Technology (MEXT), Japan. Author W.-S. Roh was supported by the EarthCARE Program, Earth Observation Research Center of JAXA. We are grateful to the three anonymous reviewers for helpful comments on the paper.

\section{APPENDIX A}

\section{Autoconversion and Accretion}

This study used two pairs of autoconversion and accretion schemes. Here, we briefly introduce these schemes, and their detailed explanations are found in the original papers. Note that all variables except for $n_{c}$ (which uses inverse centimeters cubed) are described using mks units.

NSW6 originally used an autoconversion parameterization proposed by B68. The coefficients used in the parameterization were modified by Lin et al. (1983) and Grabowski (1998). The autoconversion parameterization was finally implemented in NSW6 as follows:

$$
\begin{aligned}
\rho_{a}\left(\frac{\partial q_{c}}{\partial t}\right)_{\text {aut }} & =-16.7\left(\rho_{a} q_{c}\right)^{2}\left(5+3.6 \times 10^{-5} \frac{n_{c}}{D_{d} \rho_{a} q_{c}}\right)^{-1}, \\
D_{d} & =0.1456-5.964 \times 10^{-2} \ln \left(\frac{n_{c}}{2000}\right),
\end{aligned}
$$

where $D_{d}$ is the relative dispersion of the cloud droplet number concentration. An accretion parameterization was also imported from Lin et al. (1983) as follows:

$$
\left(\frac{\partial q_{c}}{\partial t}\right)_{\mathrm{acc}}=-q_{c} E_{\mathrm{rc}} \int_{0}^{\infty} \frac{\pi}{4} D_{r}^{2} v_{t, r}\left(D_{r}\right) N_{r}\left(D_{r}\right) d D_{r},
$$

where $E_{\mathrm{rc}}=1.0$ is the mean collision and coalescence efficiency, $D_{r}$ is the rain diameter, $v_{t, r}=130 D_{r}^{0.5}\left(\rho_{0} / \rho\right)^{1 / 2}$ is the empirically determined terminal velocity of rain droplets, and the size distribution function of rain $N_{r}\left(D_{r}\right)$ is assumed to be a Marshall-Palmer distribution. Note that the integral in Eq. (A2) is solved analytically and the final form of (A2) is shown in Tomita (2008).

The autoconversion and accretion parameterizations proposed by KK00 were formulated as follows:

$$
\begin{aligned}
& \left(\frac{\partial q_{c}}{\partial t}\right)_{\text {aut }}=1350 q_{c}^{2.47} N_{c}^{-1.79} \text { and } \\
& \left(\frac{\partial q_{r}}{\partial t}\right)_{\text {acc }}=67\left(q_{c} q_{r}\right)^{1.15} .
\end{aligned}
$$

The coefficients were optimized to reproduce marine stratocumulus simulations using a spectral bin cloud microphysics scheme.

\section{APPENDIX B}

\section{Vapor Deposition}

Vapor deposition by a single ice particle with a particle mass $x$ is described as follows (e.g., Pruppacher and Klett 1997):

$$
\left(\frac{\partial x}{\partial t}\right)_{\text {dep }}=4 \pi C G F_{v}(r) S_{i}
$$

where $C$ is the capacitance, $G$ is a thermodynamic coefficient, and $F_{v}$ is the ventilation coefficient. Assuming a small spherical particle, $C=D / 2$ and $F_{v}=1$ are good approximations. 
In bulk cloud microphysics schemes, the growth equation for mass concentrations is given by integrating the equation over the particle size distribution as follows:

$$
\begin{aligned}
\rho_{a} \frac{\partial q}{\partial t} & =\int_{0}^{\infty}\left(\frac{\partial x}{\partial t}\right)_{\mathrm{dep}} N(D) d D \\
& \propto 2 \pi G S_{i} n \bar{D},
\end{aligned}
$$

where $\bar{D}$ is the mean mass diameter (maximum dimension). Thus, in theory, the growth rate for mass concentrations is approximately proportional to the mean diameter and number concentrations of hydrometeors.

Vapor deposition is interpreted as consumption of the ice supersaturation $S_{i}$ by ice particles. The characteristic time of vapor deposition $\tau_{\mathrm{dep}}$ is defined as follows:

$$
\begin{aligned}
\frac{\partial S_{i}}{\partial t} & =-\rho_{a}\left(\frac{\partial q}{d t}\right)_{\mathrm{dep}}=-\frac{S_{i}}{\tau_{\mathrm{dep}}} \\
\tau_{\mathrm{dep}} & \equiv S_{i} / \rho_{a}\left(\frac{\partial q}{d t}\right)_{\mathrm{dep}},
\end{aligned}
$$

This study guessed the origin of the issue in the vapor deposition process using the relationship $\tau_{\text {dep }} \propto(2 \pi G n \bar{D})^{-1}$ [Eq. (B2)].

\section{APPENDIX C}

\section{Riming}

Riming occurs by collisions between ice and liquid particles. The growth rate of an ice particle with a particle radius $r$ is calculated by estimating liquid mass within the sweep volume during falling described as follows:

$$
\left(\frac{\partial x_{j}}{\partial t}\right)_{\operatorname{rim}}=\int_{0}^{\infty} E_{j, k} x_{k} \pi\left(r_{j}+r_{k}\right)^{2}\left|v_{t, j}-v_{t, k}\right| N_{k}\left(D_{k}\right) d D_{k},
$$

where $E_{j, k}$ is the collection efficiency. Thus, the growth rate of mass concentrations is described by Eq. (C1) as follows:

$$
\begin{aligned}
\rho_{a} \frac{\partial q_{j}}{\partial t} & =\int_{0}^{\infty}\left(\frac{\partial x_{j}}{\partial t}\right)_{\text {rim }} N_{j}\left(D_{j}\right) d D_{j} \\
& =\iint_{0}^{\infty} E_{j, k} x_{k} \pi\left(r_{j}+r_{k}\right)^{2}\left|v_{t, j}-v_{t, k}\right| N_{j}\left(D_{j}\right) N_{k}\left(D_{k}\right) d D_{j} d D_{k}
\end{aligned}
$$

Assuming riming between cloud and snow or cloud and graupel, Eq. (C2) is approximated with $r_{j} \gg r_{c}$ and $v_{t, j} \gg v_{t, c}(j=s, g)$. Furthermore, the terminal velocity is known to be closely related to the particle radius through the dependence of the drag coefficient on the particle radius (e.g., $v_{t, j} \propto r_{j}^{2}$ for small spherical particles according to Stokes's law): power-law relationships between $v_{t}$ and $r_{j}$ based on in situ observations $\left(v_{t, j}=c_{j} r_{j}^{d_{j}}\right)$ are generally used in cloud microphysics schemes. The riming growth rate is derived (approximately) as follows:

$$
\rho_{a} \frac{\partial q_{j}}{\partial t} \propto \overline{E_{j, c}} \pi{\overline{D_{j}}}^{2+d_{j}} n_{j} \rho q_{c}
$$

where $\overline{E_{j, c}}$ is the mean collection efficiency. The exponent $d_{j}$ generally falls within 0.1-1.0 (e.g., Locatelli and Hobbs 1974), and, specifically in NSW6, 0.25 and 0.5 are used for snow and graupel, respectively. Thus, in theory, the growth rate for mass concentrations is approximately proportional to the ice number concentrations and to the second to third power of the mean ice diameter.

\section{REFERENCES}

Austin, R. T., A. J. Heymsfield, and G. L. Stephens, 2009: Retrieval of ice cloud microphysical parameters using the CloudSat millimeter-wave radar and temperature.J. Geophys. Res., 114, D00A23, https://doi.org/10.1029/2008JD010049.

Berry, E. X., 1968: Modification of the warm rain process. Proc. First Conf. on Weather Modification, Albany, NY, Amer. Meteor. Soc., 81-85.

Bigg, E. K., 1953: The formation of atmospheric ice crystals by the freezing of droplets. Quart. J. Roy. Meteor. Soc., 79, 510-519, https://doi.org/10.1002/qj.49707934207.

_ 1973: Ice nucleus concentrations in remote areas. J. Atmos. Sci., 30, 1153-1157, https://doi.org/10.1175/1520-0469(1973) 030<1153:INCIRA $>2.0$.CO;2.

Bodas-Salcedo, A., K. D. Williams, P. R. Field, and A. P. Lock, 2012: The surface downwelling solar radiation surplus over the Southern Ocean in the Met Office model: The role of midlatitude cyclone clouds. J. Climate, 25, 7467-7486, https:// doi.org/10.1175/JCLI-D-11-00702.1.

Böhm, J. P., 1992: A general hydrodynamic theory for mixed-phase microphysics. Part III: Riming and aggregation. Atmos. Res., 28, 103-123, https://doi.org/10.1016/0169-8095(92)90023-4.

Chubb, T. H., J. B. Jensen, S. T. Siems, and M. J. Manton, 2013: In situ observations of supercooled liquid clouds over the Southern Ocean during the HIAPER Pole-to-Pole Observation campaigns. Geophys. Res. Lett., 40, 5280-5285, https://doi.org/ 10.1002/grl.50986.

Curry, J. A., J. L. Schramm, W. B. Rossow, and D. Randall, 1996: Overview of Arctic cloud and radiation characteristics. J. Climate, 9, 1731-1764, https://doi.org/10.1175/1520-0442(1996)009<1731: OOACAR $>2.0 . \mathrm{CO} ; 2$.

, and Coauthors, 2000: FIRE Arctic Clouds Experiment. Bull. Amer. Meteor. Soc., 81, 5-30, https://doi.org/10.1175/15200477(2000)081<0005:FACE > 2.3.CO;2.

DeMott, P. J., D. J. Cziczo, A. J. Prenni, D. M. Murphy, S. M. Kreidenweis, D. S. Thompson, R. Borys, and D. C. Rogers, 2003: Measurements of the concentration and composition of nuclei for cirrus formation. Proc. Natl. Acad. Sci. USA, 100, 14 655-14 660, https://doi.org/10.1073/pnas.2532677100.

Elsaesser, G. S., C. W. O’Dell, M. D. Lebsock, R. Bennartz, T. J. Greenwald, and F. J. Wentz, 2017: The multisensor advanced climatology of liquid water path (MAC-LWP). J. Climate, 30, 10 193-10 210, https://doi.org/10.1175/JCLI-D-16-0902.1.

Field, P. R., R. J. Hogan, P. R. A. Brown, A. J. Illingworth, T. W. Choularton, and R. J. Cotton, 2005: Parametrization of iceparticle size distributions for mid-latitude stratiform cloud. Quart. J. Roy. Meteor. Soc., 131, 1997-2017, https://doi.org/ 10.1256/qj.04.134.

—, R. J. Cotton, K. McBeath, A. P. Lock, S. Webster, and R. P. Allan, 2014: Improving a convection permitting model simulation of a cold air outbreak. Quart. J. Roy. Meteor. Soc., 140, 124-138, https://doi.org/10.1002/qj.2116.

Forbes, R. M., and M. Ahlgrimm, 2014: On the representation of high-latitude boundary layer mixed-phase cloud in the ECMWF 
global model. Mon. Wea. Rev., 142, 3425-3445, https://doi.org/ 10.1175/MWR-D-13-00325.1.

Furtado, K., and P. Field, 2017: The role of ice-microphysics parametrizations in determining the prevalence of supercooled liquid water in high-resolution simulations of a Southern Ocean midlatitude cyclone. J. Atmos. Sci., 74, 2001-2021, https://doi.org/ 10.1175/JAS-D-16-0165.1.

Golaz, J.-C., L. W. Horowitz, and H. Levy II, 2013: Cloud tuning in a coupled climate model: Impact on 20th century warming. Geophys. Res. Lett., 40, 2246-2251, https://doi.org/10.1002/ $\operatorname{grl} .50232$.

Grabowski, W. W., 1998: Toward cloud resolving modeling of large-scale tropical circulations: A simple cloud microphysics parameterization. J. Atmos. Sci., 55, 3283-3298, https://doi.org/ 10.1175/1520-0469(1998)055<3283:TCRMOL >2.0.CO;2.

Grosvenor, D. P., T. W. Choularton, T. Lachlan-Cope, M. W. Gallagher, J. Crosier, K. N. Bower, R. S. Ladkin, and J. R. Dorsey, 2012: In-situ aircraft observations of ice concentrations within clouds over the Antarctic Peninsula and Larsen Ice Shelf. Atmos. Chem. Phys., 12, 11275-11294, https:// doi.org/10.5194/acp-12-11275-2012.

Haarsma, R. J., and Coauthors, 2016: High Resolution Model Intercomparison Project (HighResMIP v1.0) for CMIP6. Geosci. Model Dev.,9, 4185-4208, https://doi.org/10.5194/gmd-9-4185-2016.

Harimaya, T., 1975: The riming properties of snow crystals. J. Meteor. Soc. Japan, 53, 384-392, https://doi.org/10.2151/jmsj1965.53.6_384.

Hashino, T., M. Satoh, Y. Hagihara, T. Kubota, T. Matsui, T. Nasuno, and H. Okamoto, 2013: Evaluating cloud microphysics from NICAM against CloudSat and CALIPSO. J. Geophys. Res. Atmos., 118, 7273-7292, https://doi.org/10.1002/jgrd.50564.

- , and Coauthors, 2016: Evaluating Arctic cloud radiative effects simulated by NICAM with A-train. J. Geophys. Res. Atmos., 121, 7041-7063, https://doi.org/10.1002/2016JD024775.

Heymsfield, A. J., and L. J. Donner, 1990: A scheme for parameterizing ice-cloud water content in general circulation models. J. Atmos. Sci., 47, 1865-1877, https://doi.org/10.1175/15200469(1990)047<1865:ASFPIC > 2.0.CO;2.

—_, and J. Iaquinta, 2000: Cirrus crystal terminal velocities. J. Atmos. Sci., 57, 916-938, https://doi.org/10.1175/15200469(2000)057<0916:CCTV>2.0.CO;2.

Hong, S.-Y., J. Dudhia, and S.-H. Chen, 2004: A revised approach to ice microphysical processes for the bulk parameterization of clouds and precipitation. Mon. Wea. Rev., 132, 103-120, https:// doi.org/10.1175/1520-0493(2004)132<0103:ARATIM>2.0.CO;2.

Iga, S., H. Tomita, Y. Tsushima, and M. Satoh, 2007: Climatology of a nonhydrostatic global model with explicit cloud processes. Geophys. Res. Lett., 34, L22814, https://doi.org/10.1029/ $2007 \mathrm{GL} 031048$.

Igel, A. L., M. R. Igel, and S. C. van den Heever, 2015: Make it a double? Sobering results from simulations using singlemoment microphysics schemes. J. Atmos. Sci., 72, 910-925, https://doi.org/10.1175/JAS-D-14-0107.1.

Jackson, R. C., and Coauthors, 2012: The dependence of ice microphysics on aerosol concentration in Arctic mixed-phase stratus clouds during ISDAC and M-PACE. J. Geophys. Res., 117, D15207, https://doi.org/10.1029/2012JD017668.

Kang, S. M., D. M. Frierson, and I. M. Held, 2009: The tropical response to extratropical thermal forcing in an idealized GCM: The importance of radiative feedbacks and convective parameterization. J. Atmos. Sci., 66, 2812-2827, https:// doi.org/10.1175/2009JAS2924.1.

Kawai, H., S. Yukimoto, T. Koshiro, N. Oshima, T. Tanaka, H. Yoshimura, and R. Nagasawa, 2019: Significant improvement of cloud representation in the global climate model MRI-ESM2. Geosci. Model Dev., 12, 2875-2897, https://doi.org/10.5194/gmd12-2875-2019.

Kay, J. E., C. Wall, V. Yettella, B. Medeiros, C. Hannay, P. Coldwell, and C. Bitz, 2016: Global climate impacts of fixing the Southern Ocean shortwave radiation bias in the Community Earth System Model (CESM). J. Climate, 29, 4617-4636, https:// doi.org/10.1175/JCLI-D-15-0358.1.

Khairoutdinov, M., and Y. Kogan, 2000: A new cloud physics parameterization in a large-eddy simulation model of marine stratocumulus. Mon. Wea. Rev., 128, 229-243, https://doi.org/ 10.1175/1520-0493(2000)128<0229:ANCPPI > 2.0.CO;2.

Klein, S. A., and Coauthors, 2009: Intercomparison of model simulations of mixed-phase clouds observed during the ARM Mixed-Phase Arctic Cloud Experiment. I: Single-layer cloud. Quart. J. Roy. Meteor. Soc., 135, 979-1002, https://doi.org/ 10.1002/qj.416.

Knight, C. A., W. A. Cooper, D. W. Breed, I. R. Paluch, P. L. Smith, and G. Vali, 1982: Microphysics. Hailstorms of the Central High Plains, C. Knight and P. Squires, Eds., Vol. 1, Colorado Associated University Press, 151-193.

Kodama, C., A. T. Noda, and M. Satoh, 2012: An assessment of the cloud signals simulated by NICAM using ISCCP, CALIPSO, and CloudSat satellite simulators. J. Geophys. Res., 117, D12210, https://doi.org/10.1029/2011JD017317.

—, and Coauthors, 2015: A 20-year climatology of a NICAM AMIP-type simulation. J. Meteor. Soc. Japan, 93, 393-424, https://doi.org/10.2151/jmsj.2015-024.

Kotsuki, S., K. Terasaki, H. Yashiro, H. Tomita, M. Satoh, and T. Miyoshi, 2018: Online model parameter estimation with ensemble data assimilation in the real global atmosphere: A case with the nonhydrostatic icosahedral atmospheric model (NICAM) and the global satellite mapping of precipitation data. J. Geophys. Res. Atmos., 123, 7375-7392, https://doi.org/ 10.1029/2017JD028092.

Lin, Y. L., R. D. Farley, and H. D. Orville, 1983: Bulk parameterization of the snow field in a cloud model. J. Climate Appl. Meteor., 22, 1065-1092, https://doi.org/10.1175/1520-0450(1983) 022<1065:BPOTSF $>2.0 . \mathrm{CO} ; 2$.

Locatelli, J. D., and P. V. Hobbs, 1974: Fall speeds and masses of solid precipitation particles. J. Geophys. Res., 79, 2185-2197, https://doi.org/10.1029/JC079i015p02185.

Martin, G. M., S. F. Milton, C. A. Senior, M. E. Brooks, S. Ineson, T. Reichler, and J. Kim, 2010: Analysis and reduction of systematic errors through a seamless approach to modeling weather and climate. J. Climate, 23, 5933-5957, https://doi.org/ 10.1175/2010JCLI3541.1.

McCoy, D. T., D. L. Hartmann, M. D. Zelinka, P. Ceppi, and D. P. Grosvenor, 2015: Mixed-phase cloud physics and Southern Ocean cloud feedback in climate models. J. Geophys. Res. Atmos., 120, 9539-9554, https://doi.org/10.1002/2015JD023603.

McFarquhar, G. M., and Coauthors, 2011: Indirect and SemiDirect Aerosol Campaign. Bull. Amer. Meteor. Soc., 92, 183-201, https://doi.org/10.1175/2010BAMS2935.1.

Milbrandt, J. A., and M. K. Yau, 2005: A multimoment bulk microphysics parameterization. Part I: Analysis of the role of the spectral shape parameter. J. Atmos. Sci., 62, 3051-3064, https://doi.org/10.1175/JAS3534.1.

Mioche, G., and Coauthors, 2017: Vertical distribution of microphysical properties of Arctic springtime low-level mixedphase clouds over the Greenland and Norwegian Seas. Atmos. Chem. Phys., 17, 12 845-12 869, https://doi.org/10.5194/acp-1712845-2017. 
Morrison, H., and J. O. Pinto, 2005: Mesoscale modeling of springtime Arctic mixed-phase stratiform clouds using a new two-moment bulk microphysics scheme. J. Atmos. Sci., 62, 3683-3704, https://doi.org/10.1175/JAS3564.1.

- and A. Gettelman, 2008: A new two-moment bulk stratiform cloud microphysics scheme in the Community Atmosphere Model, version 3 (CAM3). Part I: Description and numerical tests. J. Climate, 21, 3642-3659, https://doi.org/10.1175/ 2008JCLI2105.1.

_- , G. de Boer, G. Feingold, J. Harrington, M. D. Shupe, and K. Sulia, 2012: Resilience of persistent Arctic mixed-phase clouds. Nat. Geosci., 5, 11-17, https://doi.org/10.1038/ ngeo1332.

O'Dell, C. W., F. J. Wentz, and R. Bennartz, 2008: Cloud liquid water path from satellite-based passive microwave observations: A new climatology over the global oceans. J. Climate, 21, 1721-1739, https://doi.org/10.1175/2007JCLI1958.1.

Ono, A., 1969: The shape and riming properties of ice crystals in natural clouds. J. Atmos. Sci., 26, 138-147, https://doi.org/ 10.1175/1520-0469(1969)026<0138:TSARPO>2.0.CO;2.

Phillips, T. J., and Coauthors, 2004: Evaluating parameterizations in general circulation models: Climate simulation meets weather prediction. Bull. Amer. Meteor. Soc., 85, 1903-1916, https://doi.org/10.1175/BAMS-85-12-1903.

Phillips, V. T. J., L. J. Donner, and S. T. Garner, 2007: Nucleation processes in deep convection simulated by a cloudsystem-resolving model with double-moment bulk microphysics. J. Atmos. Sci., 64, 738-761, https://doi.org/ 10.1175/JAS3869.1.

Pruppacher, H. R., and J. D. Klett, 1997: Microphysics of Clouds and Precipitation. Kluwer Academic, 954 pp.

Reinking, R. F., 1979: The onset and early growth of snow crystals by accretion of droplets. J. Atmos. Sci., 36, 870-881, https://doi.org/ 10.1175/1520-0469(1979)036<0870:TOAEGO > 2.0.CO;2.

Roberts, M., and Coauthors, 2018: The benefits of global highresolution for climate simulation: Process-understanding and the enabling of stakeholder decisions at the regional scale. Bull. Amer. Meteor. Soc., 99, 2341-2359, https://doi.org/ 10.1175/BAMS-D-15-00320.1.

Roh, W., and M. Satoh, 2014: Evaluation of precipitating hydrometeor parameterizations in a single-moment bulk microphysics scheme for deep convective systems over the tropical central Pacific. J. Atmos. Sci., 71, 2654-2673, https://doi.org/ 10.1175/JAS-D-13-0252.1.

,-- , and T. Nasuno, 2017: Improvement of a cloud microphysics scheme for a global nonhydrostatic model using TRMM and a satellite simulator. J. Atmos. Sci., 74, 167184, https://doi.org/10.1175/JAS-D-16-0027.1.

, T. Hashino, H. Okamoto, and T. Seiki, 2020: Evaluations of thermodynamics phases of clouds in a cloud-system-resolving model using CALIPSO and a satellite simulator over the Southern Ocean. J. Atmos. Sci., 77, 3781-3801, https://doi.org/ 10.1175/JAS-D-19-0273.1.

Rutledge, S. A., and P. V. Hobbs, 1983: The mesoscale and microscale structure and organization of clouds and precipitation in midlatitude cyclones. VIII: A model for the "seeder-feeder" process in warm-frontal rainbands. J. Atmos. Sci., 40, 1185-1206, https://doi.org/10.1175/1520-0469(1983)040<1185:TMAMSA> 2.0.CO;2.

Sato, Y., S. Nishizawa, H. Yashiro, Y. Miyamoto, Y. Kajikawa, and H. Tomita, 2015: Impacts of cloud microphysics on trade wind cumulus: Which cloud microphysics processes contribute to the diversity in a large eddy simulation? Prog.
Earth Planet. Sci., 2, 23, https://doi.org/10.1186/s40645-0150053-6.

Satoh, M., T. Matsuno, H. Tomita, H. Miura, T. Nasuno, and S. Iga, 2008: Nonhydrostatic icosahedral atmospheric model (NICAM) for global cloud resolving simulations. J. Comput. Phys., 227, 3486-3514, https://doi.org/10.1016/j.jcp.2007.02.006.

_, T. Inoue, and H. Miura, 2010: Evaluations of cloud properties of global and local cloud system resolving models using CALIPSO and CloudSat simulators. J. Geophys. Res., 115, D00H14, https://doi.org/10.1029/2009JD012247.

— , and Coauthors, 2014: The non-hydrostatic icosahedral atmospheric model: Description and development. Prog. Earth Planet. Sci., 1, 18, https://doi.org/10.1186/s40645-014-0018-1.

—, A. T. Noda, T. Seiki, Y.-W. Chen, C. Kodama, Y. Yamada, N. Kuba, and Y. Sato, 2018: Toward reduction of the uncertainties in climate sensitivity due to cloud processes using a global non-hydrostatic atmospheric model. Prog. Earth Planet. Sci., 5, 67, https://doi.org/10.1186/s40645-018-0226-1.

— B. Stevens, F. Judt, M. Khairoutdinov, S.-J. Lin, W. M. Putman, and P. Duben, 2019: Global cloud-resolving models. Curr. Climate Change Rep., 5, 172-184, https://doi.org/10.1007/ s40641-019-00131-0.

Seifert, A., and K. D. Beheng, 2001: A double-moment parameterization for simulating autoconversion, accretion and selfcollection. Atmos. Res., 59-60, 265-281, https://doi.org/10.1016/S01698095(01)00126-0.

— terization for mixed-phase clouds. Part I: Model description. Meteor. Atmos. Phys., 92, 45-66, https://doi.org/10.1007/s00703005-0112-4.

Seiki, T., and T. Nakajima, 2014: Aerosol effects of the condensation process on a convective cloud simulation. J. Atmos. Sci., 71, 833-853, https://doi.org/10.1175/JAS-D-12-0195.1.

_- M. Satoh, H. Tomita, and T. Nakajima, 2014: Simultaneous evaluation of ice cloud microphysics and nonsphericity of the cloud optical properties using hydrometeor video sonde and radiometer sonde in situ observations. J. Geophys. Res. Atmos., 119, 6681-6701, https://doi.org/10.1002/2013JD021086.

— C. Kodama, A. T. Noda, and M. Satoh, 2015a: Improvement in global cloud-system-resolving simulations by using a doublemoment bulk cloud microphysics scheme. J. Climate, 28, 24052419, https://doi.org/10.1175/JCLI-D-14-00241.1.

,,-- M. Satoh, T. Hashino, Y. Hagihara, and H. Okamoto, 2015b: Vertical grid spacing necessary for simulating tropical cirrus clouds with a high-resolution atmospheric general circulation model. Geophys. Res. Lett., 42, 4150-4157, https:// doi.org/10.1002/2015GL064282.

Shupe, M. D., 2011: Clouds at arctic atmospheric observatories. Part II: Thermodynamic phase characteristics. J. Appl. Meteor. Climatol., 50, 645-661, https://doi.org/10.1175/2010JAMC2468.1.

Stevens, B., and Coauthors, 2019: DYAMOND: The Dynamics of the Atmospheric General Circulation Modeled on NonHydrostatic Domains. Prog. Earth Planet. Sci., 6, 61, https:// doi.org/10.1186/s40645-019-0304-z.

Suzuki, K., G. L. Stephens, S. C. van den Heever, and T. Y. Nakajima, 2011: Diagnosis of the warm rain process in cloud-resolving models using joint CloudSat and MODIS observations. J. Atmos. Sci., 68 , 2655-2670, https://doi.org/10.1175/JAS-D-10-05026.1.

_ J.-C. Golaz, and G. L. Stephens, 2013: Evaluating cloud tuning in a climate model with satellite observations. Geophys. Res. Lett., 40, 4464-4468, https://doi.org/10.1002/grl.50874.

- G. Stephens, A. Bodas-Salcedo, M. Wang, J. Golaz, T. Yokohata, and T. Koshiro, 2015: Evaluation of the warm rain formation 
process in global models with satellite observations. J. Atmos. Sci., 72, 3996-4014, https://doi.org/10.1175/JAS-D-14-0265.1.

Tan, I., and T. Storelvmo, 2016: Sensitivity study on the influence of cloud microphysical parameters on mixed-phase cloud thermodynamic phase partitioning in CAM5. J. Atmos. Sci., 73, 709-728, https://doi.org/10.1175/JAS-D-15-0152.1.

Tatebe, H., Y. Tanaka, Y. Komuro, and H. Hasumi, 2018: Impact of deep ocean mixing on the climatic mean state in the Southern Ocean. Sci. Rep., 8, 14479, https://doi.org/10.1038/ s41598-018-32768-6.

Thompson, G., P. R. Field, R. M. Rasmussen, and W. D. Hall, 2008: Explicit forecasts of winter precipitation using an improved bulk microphysics scheme. Part II: Implementation of a new snow parameterization. Mon. Wea. Rev., 136, 5095-5115, https://doi.org/10.1175/2008MWR2387.1.

Tomita, H., 2008: New microphysical schemes with five and six categories by diagnostic generation of cloud ice. J. Meteor. Soc. Japan, 86A, 121-142, https://doi.org/10.2151/jmsj.86A.121.

_ , and M. Satoh, 2004: A new dynamical framework of nonhydrostatic global model using the icosahedral grid. Fluid Dyn. Res., 34, 357-400, https://doi.org/10.1016/j.fluiddyn.2004.03.003.

Uttal, T., and Coauthors, 2002: Surface heat budget of the Arctic Ocean. Bull. Amer. Meteor. Soc., 83, 255-275, https://doi.org/ 10.1175/1520-0477(2002)083<0255:SHBOTA $>2.3$.CO;2.
vanZanten, M. C., and Coauthors, 2011: Controls on precipitation and cloudiness in simulations of trade-wind cumulus as observed during RICO. J. Adv. Model. Earth Syst., 3, M06001, https://doi.org/10.1029/2011MS000056.

Vergara-Temprado, J., and Coauthors, 2018: Strong control of Southern Ocean cloud reflectivity by ice-nucleating particles. Proc. Natl. Acad. Sci. USA, 115, 2687-2692, https://doi.org/ 10.1073/pnas.1721627115.

Verlinde, J., and Coauthors, 2007: The Mixed-Phase Arctic Cloud Experiment. Bull. Amer. Meteor. Soc., 88, 205-222, https:// doi.org/10.1175/BAMS-88-2-205.

Wacker, U., and A. Seifert, 2001: Evolution of rain water profiles resulting from pure sedimentation: Spectral vs. parameterized description. Atmos. Res., 58, 19-39, https://doi.org/10.1016/ S0169-8095(01)00081-3.

Wang, K. P., 2002: Ice Microphysics. Academic Press, 273 pp.

Williams, K. D., and Coauthors, 2013: The Transpose-AMIP II experiment and its application to the understanding of Southern Ocean cloud biases in climate models. J. Climate, 26, 3258-3274, https://doi.org/10.1175/JCLI-D-12-00429.1.

Xiao, F., T. Okazaki, and M. Satoh, 2003: An accurate semiLagrangian scheme for raindrop sedimentation. Mon. Wea. Rev., 131, 974-983, https://doi.org/10.1175/1520-0493(2003) $131<0974$ :AASSFR > 2.0.CO;2. 